San Jose State University

SJSU ScholarWorks

Master's Theses

Master's Theses and Graduate Research

Summer 2011

\title{
Food habits of harbor seals (Phoca vitulina richardii) in San Francisco Bay, California
}

Corinne Michele Gibble

San Jose State University

Follow this and additional works at: https://scholarworks.sjsu.edu/etd_theses

\section{Recommended Citation}

Gibble, Corinne Michele, "Food habits of harbor seals (Phoca vitulina richardii) in San Francisco Bay, California" (2011). Master's Theses. 4049.

DOI: https://doi.org/10.31979/etd.njyh-v6ky

https://scholarworks.sjsu.edu/etd_theses/4049

This Thesis is brought to you for free and open access by the Master's Theses and Graduate Research at SJSU ScholarWorks. It has been accepted for inclusion in Master's Theses by an authorized administrator of SJSU ScholarWorks. For more information, please contact scholarworks@sjsu.edu. 
FOOD HABITS OF HARBOR SEALS (PHOCA VITULINA RICHARDII) IN SAN FRANCISCO BAY, CALIFORNIA

\author{
A Thesis \\ Presented to \\ The Faculty of the Department of Marine Science \\ San Jose State University
}

\author{
In Partial Fulfillment \\ of the Requirements for the Degree \\ Master of Science
}

by

Corinne Michele Gibble

August 2011 
(C) 2011

Corinne Michele Gibble

ALL RIGHTS RESERVED 
The Designated Thesis Committee Approves the Thesis Titled

FOOD HABITS OF HARBOR SEALS (PHOCA VITULINA RICHARDII) IN SAN FRANCISCO BAY, CALIFORNIA

by

Corinne Michele Gibble

APPROVED FOR THE DEPARTMENT OF MARINE SCIENCE

SAN JOSÉ STATE UNIVERSITY

August 2011

Dr. James T. Harvey Department of Marine Science, San Jose State University

Dr. Gregor Cailliet Department of Marine Science, Fresno State University

Dr. Sarah Allen National Park Service 


\section{ABSTRACT \\ FOOD HABITS OF HARBOR SEALS (PHOCA VITULINA RICHARDII) IN SAN FRANCISCO BAY, CALIFORNIA \\ By Corinne Michele Gibble}

The diet of harbor seals (Phoca vitulina richardii) in San Francisco Bay (SFB) in California was examined from July 2007 to July 2008 via scat analysis. Scats were collected from five major haul-out sites; 22 species of fish and one species of crustacean were identified from 422 scats. The reliance of a non-native invasive species, Yellowfin Goby (Acanthogobius flavimanus), increased in importance in the diet. Additionally, another non-native invasive fish species, Chameleon Goby (Tridentiger trigonocephalus), was found for the first time in the diet of harbor seals in SFB. Harbor seal diet was compared between seasons, locations, and years using Spearman's rank correlations; diet was statistically different between years (1991-1992 and 2007-2008), between the pupping and non-pupping seasons, and between North SFB and South SFB haul-out locations. California Department of Fish and Game (CDFG) trawl data were also compared to harbor seal diet data and were found to be significantly correlated. 


\section{ACKNOWLEDGEMENTS}

I would like to thank the members of my committee, Jim Harvey, Greg Cailliet, and Sarah Allen for thesis support and guidance. I would also like to extend a special thank-you to my unofficial committee members, Bill Walker and Simon Brown, whose individual expertise were both generous and invaluable. Additionally, I am thankful to Kathy Hieb and the CDFG San Francisco Bay Study and the Interagency Ecological Program for the San Francisco Estuary, for comparative data and helpful advice.

This thesis would not be possible without the selflessness, zest, and countless hours spent by my sampling and sorting volunteers; especially, Crissy Dyke, Suzanne Manugian, Denise Greig, Heather Kramp, Lauren Donnelly-Crocker, and Stephanie Hughes. I am also indebted to my emotional and scientific support network comprised of Aaron Lopez, Tammy Bye, Erica Donnelly, Brian Hoover, Ashley Neway, Rosemary Romero, Casey T. Clark, Laurie Hall, Lisa Webb, Jason Webb, Kristine Williams, Julia Burrows, Colleen Young, Alex Ponik, Nicole Marsico, Cyndi Dawson, Erin Twomey, and Brett Haggerman, who would all agree that a little bit of wine and a lot of conversation can solve any scientific or life dilemma.

I would like to thank Dr. Earl and Ethyl Myers Oceanographic and Marine Biology Trust, the Student Packard Fund, the San Jose State Archimedes Scholarship, and the San Jose State Harvey Ecology Scholarship for financial support.

Lastly, I would like to thank my mother, father, sister, brother, Grandma and Grandpa Jabornik, and Grandma and Grandpa Gibble, for their constant support and 
endless enthusiasm for my work and my interests in science and academics; as well as, their unfailing laughter, inspiration, and encouragement throughout my journey. 


\section{TABLE OF CONTENTS}

List of Tables ............................................................... vii

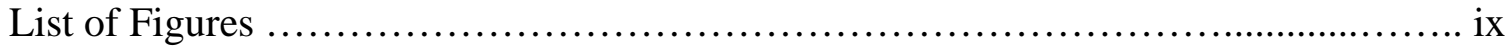

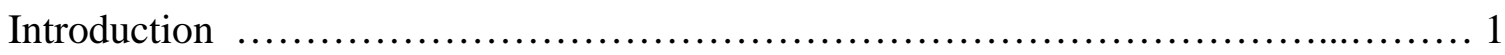

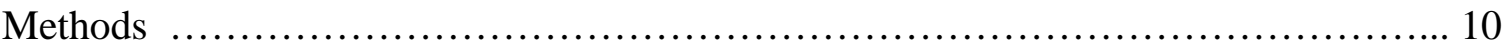

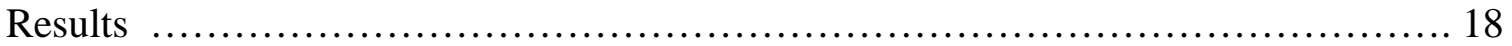

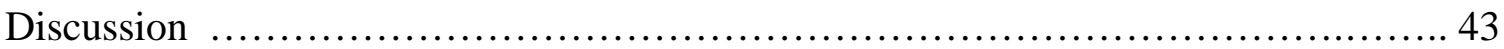

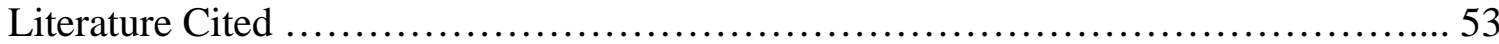




\section{LIST OF TABLES}

1. List of prey species common names, scientific names, and abbreviations........ 5

2. Diet composition of harbor seals in 1991-1992 for all haul out locations during pupping and non-pupping seasons.................................. 6

3. Diet composition of harbor seals in SSFB haul-out locations in 2007-2008 during pupping and non-pupping seasons............................... 23

4. Diet composition of harbor seals in SFB haul-out locations in 2007-2008 during pupping and non-pupping seasons................................... 29

5. Diet composition of harbor seals in NSFB haul-out locations in 2007-2008 during pupping and non-pupping seasons.............................. 30

6. Reconstructed biomass model of consumption by harbor seals in SFB in 2007-2008.

7. Reconstructed biomass model of consumption by harbor seals in SSFB in 2007-2008.

8. Reconstructed biomass model of consumption by harbor seals in NSFB in

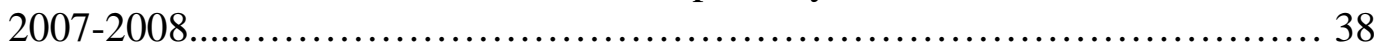




\section{LIST OF FIGURES}

1. Map of San Francisco Bay harbor seal haul-out locations...................... 3

2. California Department of Fish and Game, San Francisco Bay Study trawl sampling station map................................................ 15

3. Histogram of average fish lengths in centimeters for the top seven most important species in the diet of harbor seals in 2007-2008.................... 19

4. Species prey index curves for five most important species 2007-2008........... 20

5. Index of relative importance of harbor diets in SSFB in 2007-2008.............. 24

6. Index of Relative Importance of harbor seal diet in 1991-1992.................. 25

7. Percent number of prey species by season for harbor seal fecal samples in 2007-2008........................................................... 26

8. Percent number of prey species in the diet of harbor seals per season in

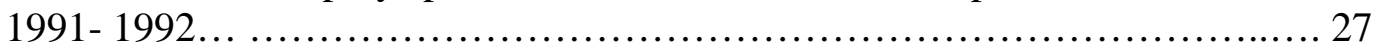

9. Index of Relative Importance of harbor seal diet in SFB in 2007-2008.......... 31

10. Index of Relative Importance of harbor seal diet in NSFB in 2007-2008......... 32

11. Number of each species per month in the diet of harbor seals $2007-2008 \ldots \ldots . . .33$

12. Number of species per month for California Department of Fish and Game trawl data in $2007-2008$ in SFB..................................... 40

13. Number of species per month for California Department of Fish and Game trawl data in 1991-1992.

14. Mean number per month of fish caught in California Department of Fish and Game trawls and percent number of fish prey in harbor seal diet in 1991-1992 and 2007-2008. 


\section{INTRODUCTION}

Pacific harbor seals (Phoca vitulina richardii) are the top predators in many marine ecosystems (Acũna and Francis 1995). As carnivorous opportunists, they feed on locally available benthic and pelagic fishes and occasionally on salmon and lamprey (Roffe and Mate 1984). Olesiuk (1993) calculated a mean daily per capita food requirement of $1.9 \mathrm{~kg}$ or $4.3 \%$ of mean body mass for harbor seals. Because their energetic needs are great, their consumption rates also may be great, which allows harbor seals to affect near-shore ecosystems, such as coastal California (Harvey 1987).

Information about harbor seal trophic interactions and resource use, therefore, is a valuable tool for evaluating the dynamics of local food webs (Arim and Naya 2003, Trites 2003).

The population of harbor seals in California has been increasing since the 1960s (Hanan 1996, Sydeman and Allen 1999, Baraff and Loughlin 2000). This increase may be in response to the protection afforded by the Marine Mammal Protection Act of 1972. The population growth rate for harbor seals, however, varies by location throughout California (Grigg 2003), and this growth rate (0.0076) may have recently slowed (Hanan 1996, Sydeman and Allen 1999, Carretta et al. 2007). From 1982 to 2000, aerial survey data collected by the California Department of Fish and Game (CDFG) indicated no significant increase in the number of harbor seals in San Francisco Bay (SFB; Hanan 1996, Grigg et al 2004, Carretta et al. 2007).

Historically harbor seals used more than 12 total haul-out locations in SFB, but some of these have now been abandoned potentially due to a depletion of local food 
sources and greater levels of disturbance (Alcorn and Fancher 1980, Allen 1991, Kopec and Harvey 1995, Grigg et al. 2004). Currently there are approximately five major harbor seal haul-out sites in San Francisco Bay (Castro Rocks, Yerba Buena Island, Corkscrew Slough, Bair Island and Mowry Slough; Fig 1.; Kopec and Harvey 1995). Three of these sites (Corkscrew Slough, Bair Island and Mowry Slough) are in South San Francisco Bay (SSFB), and two (Yerba Buena Island, Castro Rocks) are in North/Central San Francisco Bay (NSFB). Only three of these sites, Mowry Slough, Yerba Buena Island and Castro Rocks, are used by more than 100 individuals during breeding and molting (Allen 1991, Kopec and Harvey 1995, Grigg et al. 2004). Aside from the five current major haul-outs, there also are several additional smaller haul-outs that are used inconsistently. 


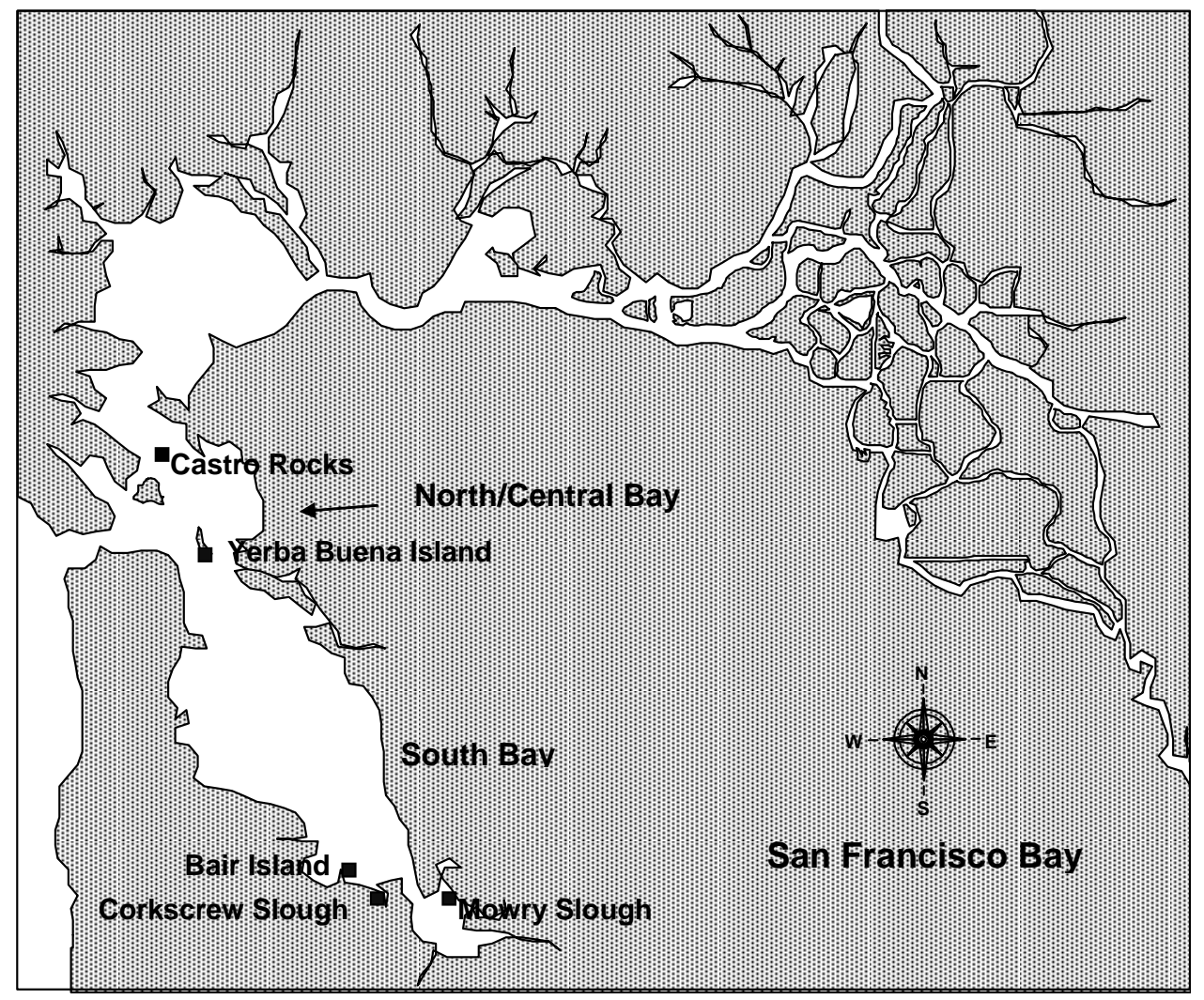

Figure 1. San Francisco Bay with sampled haul-out locations (Mowry Slough, Corkscrew Slough, Bair Island, Yerba Buena Island and Castro Rocks). This map is adapted from CDFG San Francisco Bay Study and the Interagency Ecological Program for the San Francisco Estuary, Boat Sampling Stations Map (CDFG 2010).

A number of different factors may be contributing to the minimal population growth of harbor seals in SFB, including local food depletions (Risebrough et al. 1979, Allen 1991, Allen 1993, Olesiuk 1993, Grigg et al. 2004). There has been evidence that changes in the distribution and abundance of fish populations within the bay have affected local food availability for resident seals. These local depletions have in some 
instances contributed to abandonment of haul-out areas (Allen 1991). Because of these depletions, harbor seal diet may have changed in the past decade.

The majority of the information about fish populations in SFB has been acquired through the CDFG San Francisco Bay Study and the Interagency Ecological Program for the San Francisco Estuary. In 1980, CDFG began monthly midwater and otter trawls in the bay to monitor fish populations. These surveys include 52 trawl stations, and have continued through 2011 (Torok 1994). These trawl data provide information about species composition in the bay, and has identified changes in species composition because of seasonal fluxes of transient fishes and native species.

Harbor seal diet also provides information about fish assemblages in SFB. Because they forage opportunistically, the diet of harbor seals may be a good indicator of prey species composition in the bay. Because they are generalist foragers, harbor seals consume what is readily available in their environment. A change in harbor seal consumption, therefore, may indicate a change in fish species diversity and richness. Additionally diet composition is a good measure of the impact that harbor seals may be having on fish populations in the bay. The combination of trawl data and diet data provides a means of identifying prey utilization patterns.

SFB is inhabited by a number of native and non-native species, the latter of which have been intentionally or unintentionally introduced into the bay ecosystem (Smith and Kato 1979, TBIES 2003, 2005). In 1994, Torok found that $45.1 \%$ of the diet of harbor seals in San Francisco Bay consisted of Yellowfin Goby (Acanthogobius flavimanus), an invasive species. This was the second most important prey species in the diet at that time 
(Tables 1, 2). As Torok (1994) reported, currently there is a decrease in native species

diversity and abundances in the bay, and an increase in non-native invasive species

(TBIES 2003, 2005). If the number of non-natives in the bay is increasing, this should be reflected in the diet of harbor seals.

Table 1. List of prey species common names, scientific names, and abbreviations

\begin{tabular}{lll}
\hline \hline Common Name & Scientific Name & Abbreviation \\
\hline Yellowfin Goby & Acanthogobius flavimanus & $\mathrm{Acf}$ \\
Northern Anchovy & Engraulis mordax & $\mathrm{Em}$ \\
Staghorn Sculpin & Leptocottus armatus & $\mathrm{La}$ \\
Plainfin Midshipman & Porichthys notatus & $\mathrm{Pn}$ \\
White Croaker & Genyonemus lineatus & $\mathrm{Gl}$ \\
Jacksmelt & Atherinopsis californiensis & $\mathrm{Aca}$ \\
Striped Bass & Morone saxatilis & $\mathrm{Msa}$ \\
English Sole & Parophrys vetulus & $\mathrm{Pv}$ \\
Bay Goby & Lepidogobius lepidus & $\mathrm{Lel}$ \\
Spotted Cusk-eel & Chilara taylori & $\mathrm{Ct}$ \\
Shiner Surfperch & Cymatogaster aggregata & $\mathrm{Ca}$ \\
Speckeld Sanddab & Citharichthys stigmaeus & $\mathrm{Cst}$ \\
Pile Perch & Rhacochilus vacca & $\mathrm{Rv}$ \\
Pacific Lamprey & Lampetra tridentata & $\mathrm{Lt}$ \\
Market Squid & Doryteuthis opalescens & $\mathrm{Do}$ \\
California Tonguefish & Symphurus atricauda & $\mathrm{Sat}$ \\
Topsmelt & Atherinops affinis & $\mathrm{Aa}$ \\
Pacific Herring & Clupea pallasii & $\mathrm{Chp}$ \\
Dover Sole & Microstomus pacificus & $\mathrm{Mpa}$ \\
Sand Sole & Psettichthys melanostictus & $\mathrm{Pm}$ \\
Starry Flounder & Platichthys stellatus & $\mathrm{Ps}$ \\
Night Smelt & Spirinchus starski & $\mathrm{St}$ \\
Bigfin Lanternfish & Symbolophorus californiensis & $\mathrm{Syc}$ \\
Chameleon Goby & Tridentiger trigonocephalus & $\mathrm{Tt} / \mathrm{Ig}$ \\
Cheekspot Goby & Ilypnus gilberti & $\mathrm{Tt} / \mathrm{Ig}$ \\
Salmonids & Salmonid sp. & $\mathrm{Sal}$ \\
Crangonids & Crangon sp. & $\mathrm{Crang}$ \\
& & \\
\hline & & \\
& & \\
\hline
\end{tabular}


Table 2. Diet composition of harbor seals in 1991/1992 (Torok 1994) for all haul-out locations during pupping and non-pupping seasons based on analysis of fecal samples collected in San Francisco Bay, CA ( $\mathrm{n}=153)$.

\begin{tabular}{|c|c|c|c|c|c|c|c|c|c|c|c|c|}
\hline \multirow[t]{2}{*}{ Prey } & \multicolumn{4}{|c|}{ Pupping Season } & \multicolumn{4}{|c|}{ Non-pupping Season } & \multicolumn{4}{|c|}{ Combined } \\
\hline & $\% \mathrm{M}$ & $\% \mathrm{~N}$ & $\% \mathrm{FO}$ & IRI & $\% \mathrm{M}$ & $\% \mathrm{~N}$ & $\% \mathrm{FO}$ & IRI & $\% \mathrm{M}$ & $\% \mathrm{~N}$ & $\% \mathrm{FO}$ & IRI \\
\hline Acf & 18.4 & 54.4 & 47.2 & 3436.2 & 38.4 & 54.4 & 40.4 & 3749.1 & 23.8 & 54.4 & 45.1 & 3526.8 \\
\hline Pn & 38.1 & 5.1 & 26.4 & 1140.5 & 1.1 & 0.6 & 8.5 & 14.5 & 28.1 & 4.1 & 20.9 & 673.0 \\
\hline $\mathrm{Em}$ & 2.5 & 6.6 & 20.8 & 189.3 & 0.6 & 1.5 & 17.0 & 35.7 & 2.0 & 5.4 & 19.6 & 145.0 \\
\hline $\mathrm{La}$ & 1.9 & 2.1 & 7.5 & 30.0 & 48.3 & 11.6 & 27.7 & 1659.2 & 14.4 & 4.2 & 13.7 & 254.8 \\
\hline $\mathrm{Gl}$ & 24.6 & 2.4 & 3.8 & 102.6 & 1.6 & 0.6 & 8.5 & 18.7 & 18.4 & 2.0 & 3.9 & 79.6 \\
\hline Aca & 11.8 & 1.1 & 9.4 & 121.3 & 0.0 & 0.0 & 0.0 & 0.0 & 8.6 & 0.8 & 6.5 & 61.1 \\
\hline $\mathrm{Pv}$ & 1.7 & 0.4 & 4.7 & 9.9 & 10.0 & 0.2 & 2.1 & 21.4 & 3.9 & 0.3 & 3.9 & 16.4 \\
\hline Msa & N/A & 0.4 & 5.7 & 2.3 & N/A & 0.6 & 4.3 & 2.6 & $\mathrm{~N} / \mathrm{A}$ & 0.4 & 7.8 & 3.1 \\
\hline Lel & N/A & 0.3 & 3.8 & 1.1 & N/A & 0.4 & 4.3 & 1.7 & $\mathrm{~N} / \mathrm{A}$ & 0.3 & 3.9 & 1.2 \\
\hline $\mathrm{Ct}$ & 0.7 & 0.2 & 1.9 & 1.7 & 0.0 & 0.0 & 0.0 & 0.0 & 0.5 & 0.2 & 1.3 & 0.9 \\
\hline $\mathrm{Ca}$ & 0.3 & 0.2 & 1.9 & 1.0 & 0.0 & 0.0 & 0.0 & 0.0 & 0.3 & 0.1 & 1.3 & 0.5 \\
\hline Cst & 0.1 & 0.1 & 1.9 & 0.4 & 0.0 & 0.0 & 0.0 & 0.0 & 0.1 & 0.1 & 1.3 & 0.3 \\
\hline $\mathrm{Rv}$ & 0.1 & 0.1 & 0.9 & 0.2 & 0.0 & 0.0 & 0.0 & 0.0 & 0.1 & 0.1 & 0.7 & 0.1 \\
\hline $\mathrm{Lt}$ & N/A & 0.1 & 0.9 & 0.1 & N/A & 0.0 & 0.0 & 0.0 & $\mathrm{~N} / \mathrm{A}$ & 0.1 & 0.7 & 0.1 \\
\hline Do & 0.1 & 0.1 & 0.9 & 0.2 & 0.0 & 0.0 & 0.0 & 0.0 & 0.1 & 0.1 & 0.7 & 0.1 \\
\hline Sat & 0.0 & 0.0 & 0.0 & 0.0 & 0.0 & 0.0 & 0.0 & 0.0 & 0.0 & 0.0 & 0.0 & 0.0 \\
\hline Aa & 0.0 & 0.0 & 0.0 & 0.0 & 0.0 & 0.0 & 0.0 & 0.0 & 0.0 & 0.0 & 0.0 & 0.0 \\
\hline Chp & 0.0 & 0.0 & 0.0 & 0.0 & 0.0 & 0.0 & 0.0 & 0.0 & 0.0 & 0.0 & 0.0 & 0.0 \\
\hline Mpa & 0.0 & 0.0 & 0.0 & 0.0 & 0.0 & 0.0 & 0.0 & 0.0 & 0.0 & 0.0 & 0.0 & 0.0 \\
\hline $\mathrm{Pm}$ & 0.0 & 0.0 & 0.0 & 0.0 & 0.0 & 0.0 & 0.0 & 0.0 & 0.0 & 0.0 & 0.0 & 0.0 \\
\hline Ps & 0.0 & 0.0 & 0.0 & 0.0 & 0.0 & 0.0 & 0.0 & 0.0 & 0.0 & 0.0 & 0.0 & 0.0 \\
\hline St & 0.0 & 0.0 & 0.0 & 0.0 & 0.0 & 0.0 & 0.0 & 0.0 & 0.0 & 0.0 & 0.0 & 0.0 \\
\hline Syc & 0.0 & 0.0 & 0.0 & 0.0 & 0.0 & 0.0 & 0.0 & 0.0 & 0.0 & 0.0 & 0.0 & 0.0 \\
\hline $\mathrm{Tt} / \mathrm{Ig}$ & 0.0 & 0.0 & 0.0 & 0.0 & 0.0 & 0.0 & 0.0 & 0.0 & 0.0 & 0.0 & 0.0 & 0.0 \\
\hline Sal & N/A & N/A & N/A & N/A & N/A & N/A & N/A & N/A & $\mathrm{N} / \mathrm{A}$ & $\mathrm{N} / \mathrm{A}$ & N/A & N/A \\
\hline Crang & N/A & N/A & $\mathrm{N} / \mathrm{A}$ & N/A & N/A & N/A & N/A & N/A & $\mathrm{N} / \mathrm{A}$ & $\mathrm{N} / \mathrm{A}$ & N/A & N/A \\
\hline
\end{tabular}

Each prey item is presented in percent mass $(\% \mathrm{M})$, percent number $(\% \mathrm{~N})$, percent

frequency of occurrence $(\% \mathrm{FO})$, and index of relative importance $(\% \mathrm{IRI})$. Refer to Table

1 for names of species. Prey species are listed in order of IRI magnitude. 
Harbor seal diet and consumption rates vary between non-pupping and pupping seasons (Torok 1994, Nickel 2003). Males, females, and pups exhibit different foraging behavior and encounter different prey types during pupping season due to restricted movements (Boness et al. 1994, Van Parijs et al. 1997, Bowen et al. 1999, Nickel 2003). Pups are born in spring, and are nursed by their mothers for approximately four weeks until they are weaned (Reeves et al. 2002) but they can swim at birth. Nevertheless, the pupping season appears to constrain the range of nursing females. During pupping, females restrict their movements in the early portion of the lactation period. Radiotagged seals indicated a degree of site fidelity to a small number of haul-out sites during pupping season, and traveled more widely and used a greater number of haul-out sites during non-pupping season. Conversely, males are widely dispersed during female lactation (Van Parijs 1997, Boness et al. 2006). In SFB, Torok (1994) also found the diet of harbor seals changed between pupping and non-pupping seasons. Because of the change in foraging behavior during the pupping season, there may be less variability of prey in the diet during pupping season and increased variability during the non-pupping season when females may range widely when they are no longer constrained by lactation duties at rookeries.

Additionally harbor seal diet may vary by location. Harbor seals in SFB exhibit site fidelity and remain near their haul-out locations at most times, with the exception of extended foraging trips outside of the bay (Nickle 2003). SSFB and NSFB have different habitats, therefore, a difference in dominant prey species may occur, as some fish species prefer particular habitats (McCoy and Bell 1991, Friedlander and Parrish 1998). SSFB is 
dominated by salt ponds and tidal marshes with relatively shallow waters (TBIES 2003, 2005). Conversely, NSFB contains rocky outcrops surrounded by deep water, various bottom sediments (Krone 1996), and stronger currents (Petzrick et al. 1996). Because different species of fish utilize different types of habitats, there may be a difference in dominance of prey type in areas with differing habitat structure in SFB (Feyrer et al. 2007). Correspondingly, harbor seal diet may differ in foraging areas with varying habitat type and associated prey dominance (Bowen et al. 2002, Feyrer et al. 2007).

Based on the data above, I hypothesized that 1) the diet of harbor seals in SFB has changed since it was last evaluated by Torok (1994), 2) harbor seal diet would reflect the abundance and distribution of fishes within the bay as determined by midwater and bottom trawls conducted by CDFG, 3) there would be less variability in the diet and an increase of non-native invasive fish species in the diet, 4) the harbor seal diet would vary between pupping and non-pupping seasons with less variability of diet during pupping season and increased variability during the mating season, and 5) diet would vary by location such that the diet of seals of NSFB and SSFB varies according to habitat structure.

Fecal analysis was used to address the above hypotheses. Examining harbor seal scat is a non-invasive technique used to assess diet composition. Diet can be determined using skeletal remains, otoliths, and beaks found in scats (Tollit et al. 1997, Marcus et al. 1998, Bowen 2000, Orr and Harvey 2001, Laake et al. 2002, Hume et al. 2004). This method of analysis has been used commonly to evaluate the diet of phocids, and it allows 
for species identification and estimation of prey length and mass (Pitcher 1980, Tollit et al. 1997, Harvey et al. 2000, Orr and Harvey 2001). 


\section{METHODS}

To determine diet, harbor seal scat samples $(\mathrm{n}=422)$ were collected from the five major haul-outs areas currently used by harbor seals in SFB. Two of these locations were located in NSFB (Yerba Buena Island and Castro Rocks) and three were located in SSFB (Mowry Slough, Corkscrew Slough, and Bair Island). These five locations collectively will be referred to as "San Francisco Bay" (SFB). Of the 422 samples, 230 (52.0\%) were collected from SSFB haul-out sites and 212 (48\%) were collected from NSFB haul-out sites. One hundred and two (23.1\%) of the 442 samples were collected during pupping season (March 15-May 31), whereas 340 (76.9\%) were collected during non-pupping season (June 1 - March 14). Fecal samples from each site were collected twice monthly from July 2007 to July 2008 . Fecal samples were frozen and stored until analysis.

Two methods were used to process scats. The first method was a traditional use of sieves. Each scat was processed through a series of nested sieves $(2.0,1.0$ and $0.5 \mathrm{~mm}$ mesh), and then sorted (Murie and Lavigne 1985, Harvey 1987, Torok 1994, Oxman 1995, Phillips 2005). This method has a prey item loss rate of 5\% (Orr et al. 2003). The second method involved the use of a washing machine (Orr et al. 2003), in which individual scats were placed into fine-mesh bags ( 1 gallon, 85-95 mesh nylon paint strainers; Triamco Company, Durham, N.C.), and each bag was secured closed with zip ties. A maximum of 15 samples per cycle were loaded into the washing machine (Whirlpool Commercial Quality super-capacity top loading 4 speed/9cycle). The samples were run through the "gentle cycle" using warm water on the "small load" setting (Orr et al. 2003). The washed scats were then emptied into a $0.5 \mathrm{~mm}$ mesh sieve 
and sorted. The bags were examined for extraneous parts stuck to the mesh, and washed with water over the sieve. This method decreases processing time by $58.3 \%$ and tends to loose approximately $5 \%$ of all prey items, which is the same rate of loss as the traditional use of sieves (Orr et al. 2003).

Prey hard parts (otoliths, bones, jaws, and crustacean tails) recovered from the scats were identified to species and enumerated using the Moss Landing Marine Labs (MLML) reference collections, the National Marine Mammal Laboratory (NMML) reference collection, and pertinent literature (Harvey 1987, Torok 1994, Oxman 1995). Identifications of representative samples of each species were checked and validated by William Walker at the National Marine Mammal Laboratory (NMML) in Seattle, Washington. Species found in the diet were given abbreviation codes for brevity (Table $1)$.

The all-structures technique was used to examine all hard parts in all scat samples. The minimum number of prey was determined using the greatest number of left or right otoliths, number of vertebrae, number of jaws, and for crustacean species, by number of tails (MNI; Torok 1994, Oxman 1995, Lance et al. 2001). Otoliths were measured to the nearest $0.1 \mathrm{~mm}$ using Image J (Scion Corporation). The mass and length of the consumed prey were estimated using regressions of otolith length to fish standard length (SL) and mass (Harvey et al. 2000), and correction factors for otolith number and otolith length were applied (Harvey 1989, Phillips 2005). If published regressions were not available, regressions were created using data from J. Harvey (J. Harvey, unpublished data). For 
non-otolith hard parts (bones, jaws, crustacean tails), correction factors were not available and could not be applied.

The standard parameters utilized in diet analysis are: percent mass (\%M), percent number $(\% \mathrm{~N})$, and percent frequency of occurrence $(\% \mathrm{FO})$ (Hyslop 1980, Lance et al. 2001). The metric $\% \mathrm{M}$ is calculated as:

$$
\% M_{i}=100 \bullet \frac{M_{i}}{\sum_{i}^{j} M}
$$

where the number of prey in a scat $\left(M_{i}\right)$ is divided by the sum of all prey, $i$ to $j$, and then is multiplied by 100 to yield a percentage (Hyslop 1980, Lance et al. 2001). The metric $\% \mathrm{~N}$ is calculated as:

$$
\% N_{i}=100 \bullet \frac{N_{i}}{\sum_{i}^{j} N}
$$

where the number of prey in a sample $\left(N_{i}\right)$ is divided by the sum of all prey, $i$ to $j$, and then is multiplied by 100 to yield a percentage (Hyslop 1980, Lance et al. 2001). Percent frequency of occurrence is calculated as:

$$
F O_{i}=\frac{\sum_{k-1}^{s} o_{i k}}{s}
$$

Where $O_{i}=1$ if taxon $i$ is absent in fecal $k, 1$ if taxon $i$ is present in fecal $k$, and $s=$ total number of fecal samples that contained prey (Lance et al. 2001). The Index of Relative 
Importance (IRI) can be calculated by utilizing these three metrics, $\% \mathrm{~N}, \% \mathrm{M}$ and $\% \mathrm{FO}$ using the following equation (Cailliet et al. 1986):

$$
\% \mathrm{~N}+\% \mathrm{M} * \% \mathrm{FO}=\mathrm{IRI}
$$

IRI was used to calculate prey importance in the diet (Pinkas et al. 1971, Cailliet et al. 1986). For species whose mass could not be calculated (crangonids, salmonids and lamprey), $\% \mathrm{~N}, \% \mathrm{FO}$, and a modified $\% \mathrm{IRI}(\% \mathrm{~N} * \% \mathrm{FO})$ were calculated separately. Spearman's Rank Correlation Coefficient $\left(\mathrm{r}_{s}\right)$ was calculated to compare the relative importance of major prey items in the diet among years, seasons, and locations (Sokal and Rohlf 1995, Cortez 1997, Zar 1999), where the null hypothesis was no relationship between the two sets of data, and the alternative hypothesis was a relationship between the two sets of data. For each comparison, \%IRI of major prey items in the diet was transformed to ranks. Additionally, this method of correlation was used to compare diet with trawl data; however, $\% \mathrm{~N}$, rather than $\%$ IRI was used due to data constraints. Spearman's Rank Correlation Coefficient was calculated as follows:

$$
r_{s}=1-\frac{6 \sum_{i=1}^{n} d_{i}^{2}}{n^{3}-n}
$$

and

$$
d i=\operatorname{rank}\left(\% I R I_{a i}\right)-\operatorname{rank}\left(\% I R I_{b i}\right)
$$

where $d_{i}$ is the difference between the ranked \%IRI of a prey (i) between groups $a$ and $b$, and $n$ is the number of rankings (Lance et al. 2001). Statistical significance was 
computed with R (R-Project Organization). P-values are reported relative to $\alpha$-level $(0.05)$

To determine the number of scats needed to adequately describe the diet and to capture the variation in IRI, a Sample Prey Index (SPI) curve was plotted using R. The SPI curve was generated by plotting the IRI by the number of scats. This was determined for the five most important species in the diet by plotting the bootstrapped mean and standard deviation of the IRI for consecutive samples as a function of sample size (Boyle 2010, S. Brown, personal communication, January 15, 2011, J. Harvey, personal communication January 21, 2011). Where the line becomes asymptotic and where the standard deviation becomes minimal, indicates number of scats needed to adequately describe the diet.

CDFG provided data for monthly midwater and otter trawls conducted in the bay. Tow duration was 5 min at 2 -3 knots (CDFG, unpublished data, TBIES 2003, 2005). Of 52 trawl stations, 18 were compared with diet data (Fig. 2). Data were used from trawl stations in proximity to harbor seal haul-out sites in SSFB and NSFB. To test whether harbor seal diet reflects the abundance and distribution of fishes within the bay, and whether diet varies seasonally with prey fluxes, the relationships between trawl and diet data were examined using SRC and graphical representations (Krebs 1999, Zar 1999). 


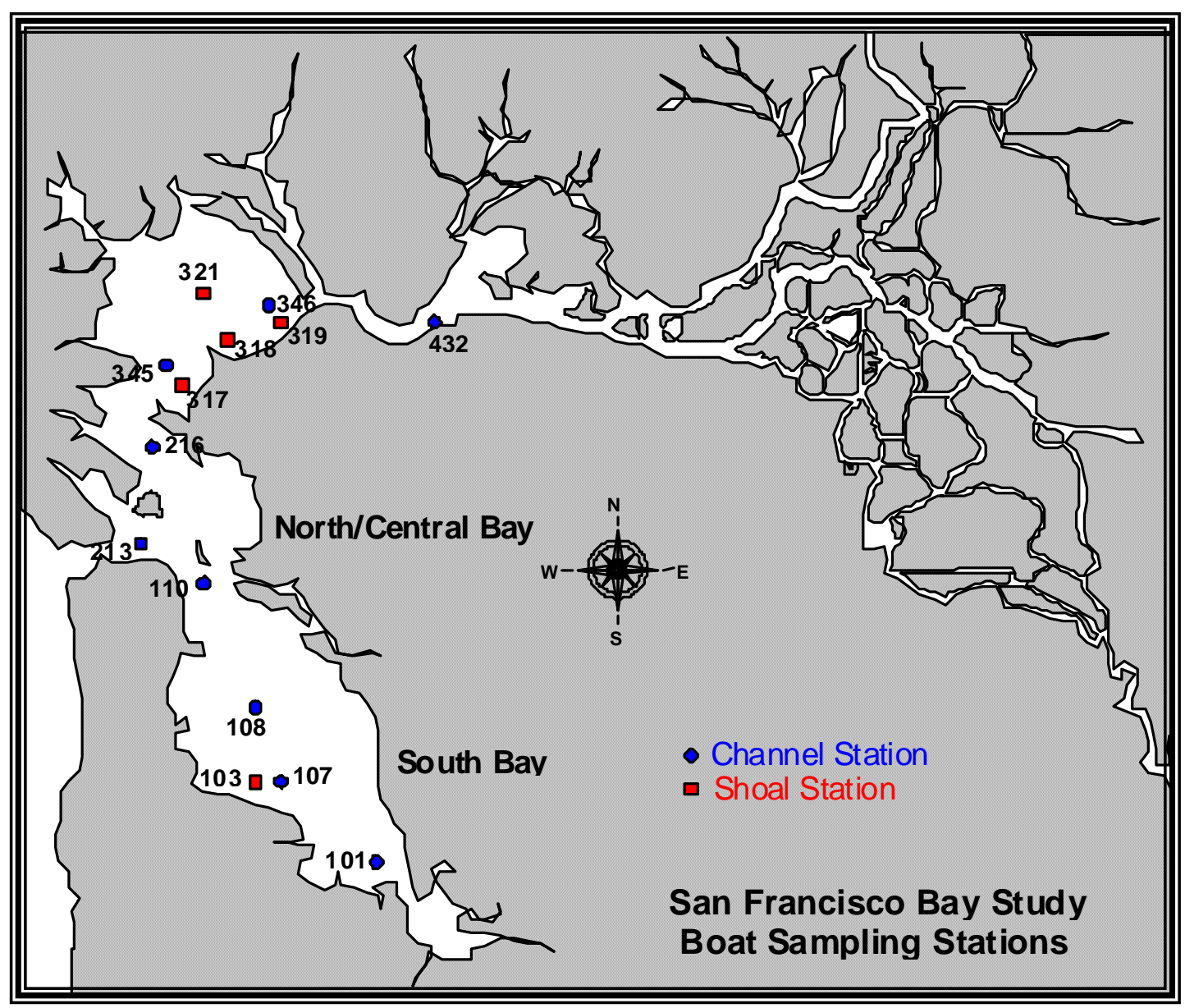

Figure 2. CDFG San Francisco Bay Study - trawl sampling stations used for comparison.

The map is adapted from CDFG San Francisco Bay Study and the Interagency Ecological Program for the San Francisco Estuary, Boat Sampling Stations Map (CDFG 2010).

A study done by Torok (1994) was used as prior information to test whether harbor seal diet has changed in SFB and if harbor seals now consume a greater abundance of invasive species. IRIs for both studies were calculated and compared (Zar 1999, Gotelli and Ellison 2004), and SRCs were calculated (Zar 1999). Torok (1994) collected harbor seal fecal samples from February 1991 until January 1992 from SSFB. 
Because Torok (1994) only sampled south bay haul-out sites (South Bay $\sim \mathrm{n}=140$, Central Bay $\sim \mathrm{n}=10$ ), I only compared my data for SSFB sites with his results. To evaluate whether there were differences in diet between pupping and non-pupping seasons and between NSFB and SSFB locations SRCs were calculated and IRIs compared.

IRI can be used in conjunction with other metrics to provide a more complete view of diet. Phillips and Harvey (2009) found the Reconstructed Biomass Model (RBM: Harvey 1987, Hammond and Rothery 1996), was the most appropriate consumption model for dietary analysis of free-ranging pinnipeds, when compared with other models such as the split-sample frequency of occurrence (SSFO; Olesiuk et al. 1993), particularly when applying the all-structure technique and correction factors. Therefore, RBM rather than SSFO was used in this study to estimate consumption by harbor seals. Both of these indices are used to calculate the biomass of prey consumed by harbor seals during a certain time period (Lance et al.2001). RBM is calculated using the equation:

$$
\prod_{i}=\frac{\sum_{k=1}^{s} b_{i k}}{\sum_{k=1}^{s} b_{k}}
$$

where $b i k=$ biomass of prey taxon $i$ in fecal sample $k, b k=$ biomass of all prey taxa in fecal $k$, and $s=$ total number of fecal samples that contained prey (Lance et al. 2001). RBM tends to underestimate small prey in medium quantities, and has a tendency to overestimate large prey items (Laake et al. 2002, Joy et al. 2006, Phillips and Harvey 
2009). This model employs estimates of species biomass from each discrete scat sample, as a proportion of the total biomass consumed (Phillips and Harvey 2009). 


\section{RESULTS}

Of 442 fecal samples, 268 (60.6\%) contained identifiable hard parts. Two hundred thirty of these samples were collected from SSFB, and of these, 127 contained identifiable hard parts (55.2\%). An additional 212 samples were collected from NFSB, and of these, 141 contained identifiable hard parts $(66.5 \%)$.

Twenty-two species of fish and one species of crustacean were identified from SFB. There were no cephalopods found in the diet. The prey species found in the diet were mostly of juvenile age classes (Fig. 3). 


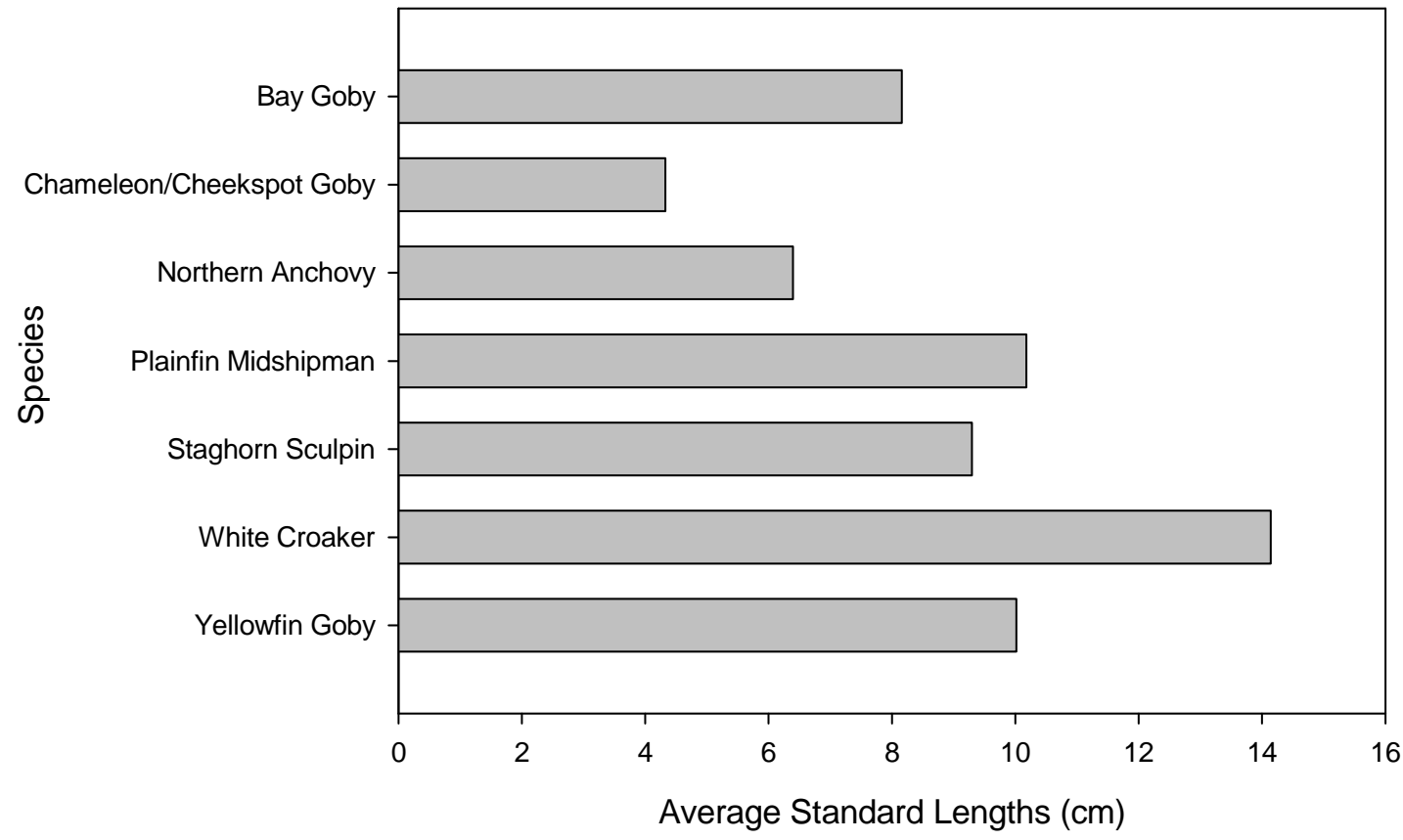

Figure 3: Histogram of average fish lengths in centimeters for the top 7 most important species in the diet of harbor seals from 2007/2008.

SPI curves calculated for the five most important species for locations combined: Yellowfin Goby, Bay Goby (Lepidogobius lepidus), Chameleon/Cheekspot goby (Tridentiger trigonocephalus/Ilypnus gilberti), Plainfin Midshipman (Porichthys notatus), and Northern Anchovy (Engraulis mordax), indicated that samples sizes were sufficient to describe the diet of harbor seals. All lines and standard deviations leveled at approximately 75 samples or fewer depending on the species (Fig 4). 

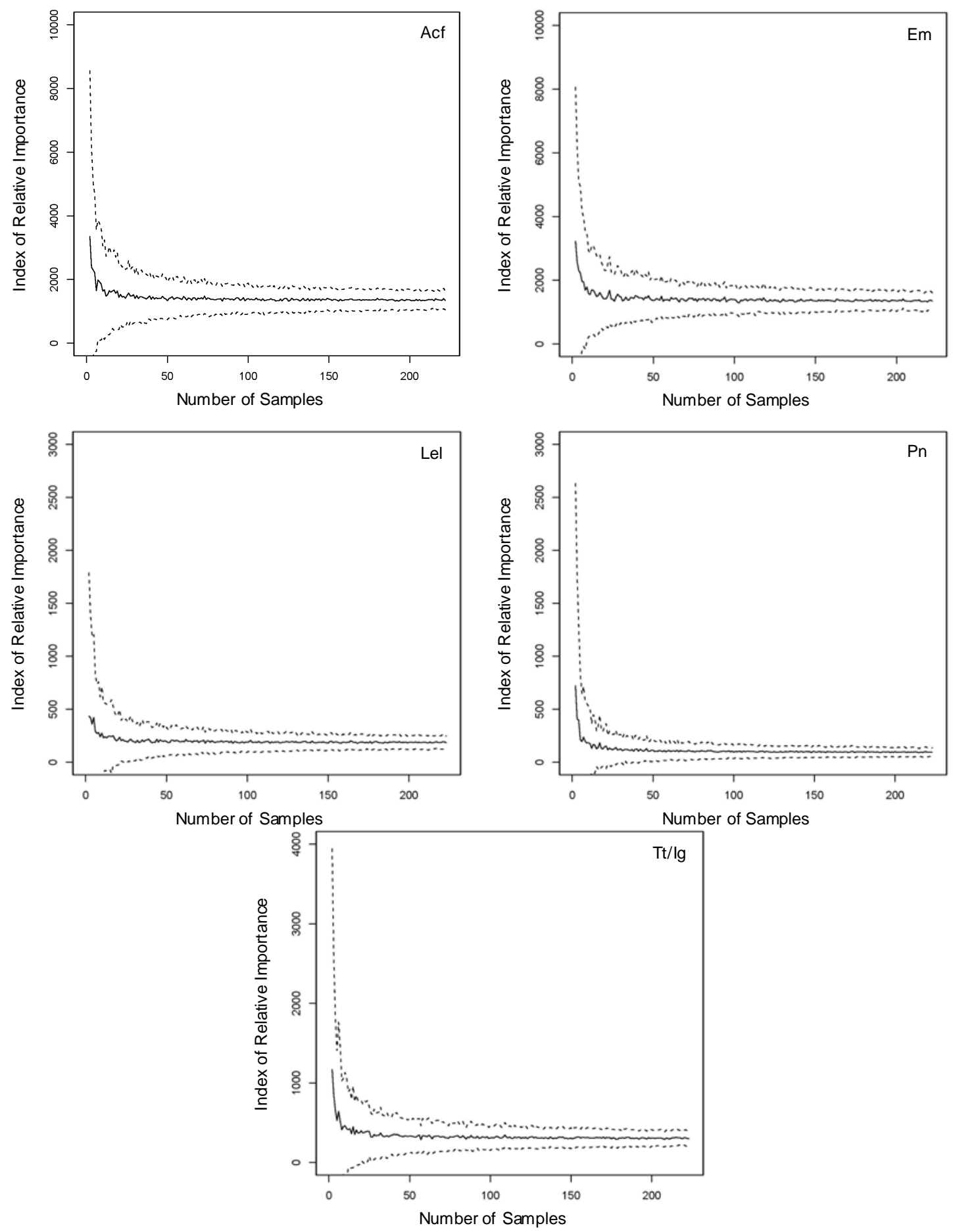

Figure 4. Species Prey Index (SPI) curves for five most important species \pm SD for fecal samples collected 2007-2008. IRI for each species is plotted vs. number of samples. 
Cheekspot/Chameleon goby, identified as Tt/Ig (Table 1), were considered as a combination of these two species because there was insufficient species-specific delineation during the identification process. Because there were insufficient Cheekspot goby reference materials, a close similarity between the otoliths of the two species, and because otoliths were indistinguishable in an eroded state, I classified this group conservatively as a combination of T. trigonocephalus / I. gilberti. Because these species were found in similar numbers in the CDFG trawl data, it is reasonable to assume that the seals would be consuming each species in the similar numbers.

Salmon were identified in the diet of harbor seals by vertebrae only. There were no salmon otoliths found in any of the fecal samples at any location. Unidentified salmon were enumerated to genus level (Oncorhynchus spp.), but could not be delineated further. I classified this group as "unidentified salmon."

The appearance of salmon in the diet was one example of how the diet of harbor seals changed since it was last studied by Torok (1994), whose study during 1991 and 1992 examined scat samples collected almost exclusively in SSFB. SRCs indicated a significant difference in prey rankings between data of Torok (1994) and my study (P > 0.05), and the diet of harbor seals in SSFB during pupping and non-pupping season (2007/2008) were significantly different than reported by Torok during pupping and nonpupping season (1991/1992). In addition to the SRC results, IRIs also indicated a difference between the diet in 1991/1992 (Torok 1994) and the diet in 2007/2008 in SSFB during pupping, non-pupping, and combined showed both numerically (Tables 2, 3) and visually using IRI diagrams (Figures 5, 6). Seasonal differences between the diet 
in $1991 / 1992$ and $2007 / 2008$ also was highlighted graphically using the metric $\% \mathrm{~N}$

(Figures 7,8). These findings confirm hypotheses 1 and 3, that the diet would change from that evaluated by Torok (1994), and that there would be an increase in non-native invasive species and a decrease in species diversity. 
Table 3. Diet composition of harbor seals for SSFB locations (Corkscrew Slough, Mowry Slough, Bair Island) during pupping and non-pupping seasons based on analysis of fecal samples ( $\mathrm{n}=230)$ collected in San Francisco Bay, California, from June 2007 to July 2008.

\begin{tabular}{|c|c|c|c|c|c|c|c|c|c|c|c|c|}
\hline \multirow[t]{2}{*}{ Prey } & \multicolumn{4}{|c|}{ Pupping Season } & \multicolumn{4}{|c|}{ Non-pupping Season } & \multicolumn{4}{|c|}{ Combined } \\
\hline & $\% \mathrm{M}$ & $\% \mathrm{~N}$ & $\% \mathrm{FO}$ & IRI & $\% \mathrm{M}$ & $\% \mathrm{~N}$ & $\% \mathrm{FO}$ & IRI & $\% \mathrm{M}$ & $\% \mathrm{~N}$ & $\% \mathrm{FO}$ & IRI \\
\hline Acf & 35.3 & 28.1 & 38.5 & 2439.5 & 56.2 & 56.2 & 67.6 & 7609.7 & 57.2 & 53.5 & 64.7 & 7157.6 \\
\hline $\mathrm{Tt} / \mathrm{Ig}$ & 3.0 & 1.0 & 7.7 & 30.7 & 19.4 & 19.4 & 30.4 & 1176.8 & 15.2 & 17.1 & 27.6 & 892.0 \\
\hline Lel & 2.3 & 2.1 & 7.7 & 34.1 & 8.2 & 8.2 & 36.3 & 598.3 & 6.5 & 7.5 & 32.8 & 459.1 \\
\hline $\mathrm{Ca}$ & 37.9 & 35.8 & 38.5 & 2836.9 & 2.1 & 2.1 & 2.9 & 12.4 & 6.1 & 5.9 & 6.9 & 82.4 \\
\hline Gl & 0.0 & 0.0 & 0.0 & 0.0 & 3.2 & 3.2 & 3.9 & 25.0 & 4.0 & 3.7 & 4.3 & 33.0 \\
\hline $\mathrm{Pv}$ & 4.7 & 6.7 & 7.7 & 87.7 & 2.2 & 2.2 & 5.9 & 25.7 & 1.8 & 2.7 & 6.0 & 27.0 \\
\hline $\mathrm{La}$ & 0.8 & 8.2 & 15.4 & 139.3 & 2.0 & 2.0 & 3.9 & 15.7 & 1.8 & 2.7 & 5.2 & 23.4 \\
\hline Sal & N/A & 0.5 & 9.1 & 4.3 & N/A & 2.1 & 9.4 & 19.4 & N/A & 1.9 & 9.4 & 17.9 \\
\hline Em & 8.2 & 10.3 & 15.4 & 285.4 & 1.2 & 1.2 & 2.0 & 4.9 & 1.9 & 2.3 & 3.4 & 14.4 \\
\hline Msa & 7.7 & 7.7 & 7.7 & 118.3 & 2.0 & 2.0 & 2.0 & 7.7 & 2.6 & 2.6 & 2.6 & 13.4 \\
\hline Pm & 0.0 & 0.0 & 0.0 & 0.0 & 0.3 & 0.3 & 4.9 & 3.4 & 0.5 & 0.3 & 4.3 & 3.5 \\
\hline Мра & 0.0 & 0.0 & 0.0 & 0.0 & 1.0 & 1.0 & 1.0 & 1.9 & 0.9 & 0.9 & 0.9 & 1.5 \\
\hline $\mathrm{Pn}$ & 0.0 & 0.0 & 0.0 & 0.0 & 1.0 & 1.0 & 1.0 & 1.9 & 0.9 & 0.9 & 0.9 & 1.5 \\
\hline Crang & N/A & 0.0 & 0.0 & 0.0 & N/A & 0.8 & 1.9 & 1.6 & N/A & 0.8 & 1.7 & 1.3 \\
\hline $\mathrm{Aa}$ & 0.0 & 0.0 & 0.0 & 0.0 & 0.1 & 0.1 & 1.0 & 0.3 & 0.1 & 0.1 & 0.9 & 0.2 \\
\hline Aca & 0.0 & 0.0 & 0.0 & 0.0 & 0.0 & 0.0 & 1.0 & 0.0 & 0.3 & 0.0 & 0.9 & 0.2 \\
\hline Ps & 0.0 & 0.0 & 0.0 & 0.0 & 0.0 & 0.0 & 1.0 & 0.1 & 0.2 & 0.0 & 0.9 & 0.2 \\
\hline $\mathrm{Ct}$ & 0.0 & 0.0 & 0.0 & 0.0 & 0.0 & 0.0 & 0.0 & 0.0 & 0.0 & 0.0 & 0.0 & 0.0 \\
\hline Cst & 0.0 & 0.0 & 0.0 & 0.0 & 0.0 & 0.0 & 0.0 & 0.0 & 0.0 & 0.0 & 0.0 & 0.0 \\
\hline $\mathrm{Rv}$ & 0.0 & 0.0 & 0.0 & 0.0 & 0.0 & 0.0 & 0.0 & 0.0 & 0.0 & 0.0 & 0.0 & 0.0 \\
\hline $\mathrm{Lt}$ & $\mathrm{N} / \mathrm{A}$ & 0.0 & 0.0 & 0.0 & N/A & 0.0 & 0.9 & 0.0 & N/A & 0.0 & 0.9 & 0.0 \\
\hline Do & 0.0 & 0.0 & 0.0 & 0.0 & 0.0 & 0.0 & 0.0 & 0.0 & 0.0 & 0.0 & 0.0 & 0.0 \\
\hline Sat & 0.0 & 0.0 & 0.0 & 0.0 & 0.0 & 0.0 & 0.0 & 0.0 & 0.0 & 0.0 & 0.0 & 0.0 \\
\hline Chp & 0.0 & 0.0 & 0.0 & 0.0 & 0.0 & 0.0 & 0.0 & 0.0 & 0.0 & 0.0 & 0.0 & 0.0 \\
\hline St & 0.0 & 0.0 & 0.0 & 0.0 & 1.0 & 1.0 & 1.0 & 1.9 & 0.0 & 0.0 & 0.0 & 0.0 \\
\hline Syc & 0.0 & 0.0 & 0.0 & 0.0 & 0.0 & 0.0 & 0.0 & 0.0 & 0.0 & 0.0 & 0.0 & 0.0 \\
\hline
\end{tabular}

Each prey item is represented using percent mass $(\% \mathrm{M}),(\% \mathrm{~N})$, percent frequency of occurrence $(\% \mathrm{FO})$, and index of relative importance (\%IRI). Data are ranked high to low according to \%IRI for combined seasons. Refer to Table 1 for names of species. Prey species are listed in order of IRI magnitude. 
A. SSFB, all seasons

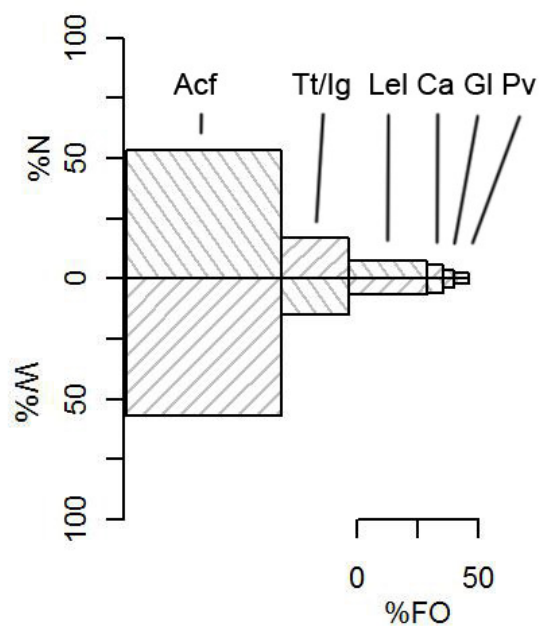

B. SSFB, non-pupping

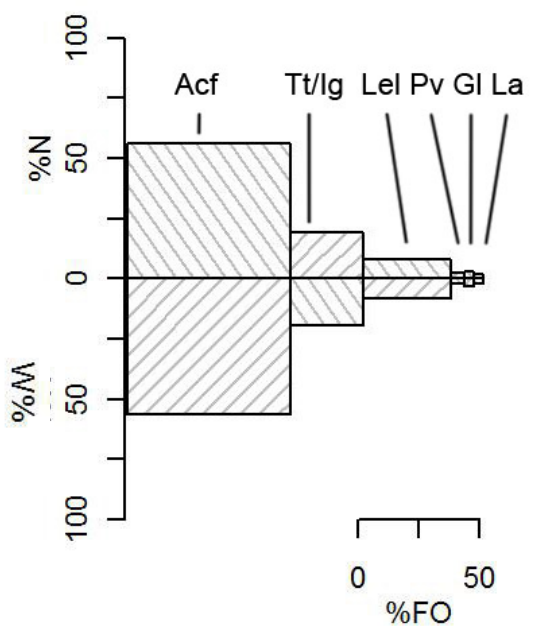

C. SSFB, pupping

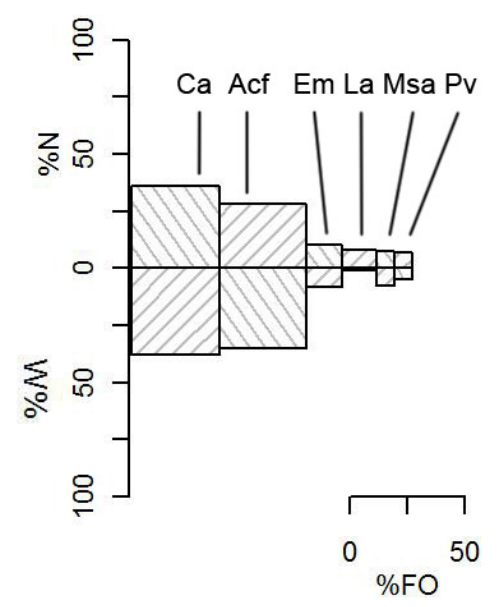

Figure 5. Index of Relative Importance (IRI) of harbor diets (2007/2008) in SSFB; data from all South Bay locations during all seasons from July 2007 - July 2008 (A), for data from all South Bay locations during non-pupping season (B), and all South Bay locations during pupping season $(\mathrm{C})$; where, Acf $=$ Yellowfin Goby, $\mathrm{Ca}=$ Shiner Surfperch, Em = Northern Anchovy, Gl = White Croaker, $\mathrm{La}=$ Staghorn Sculpin, Lel = Bay Goby, Msa $=$ Striped Bass, $\mathrm{Pv}=$ English Sole, $\mathrm{Tt} / \mathrm{Ig}=$ Chameleon/Cheekspot Goby. 
A. Torok, all seasons

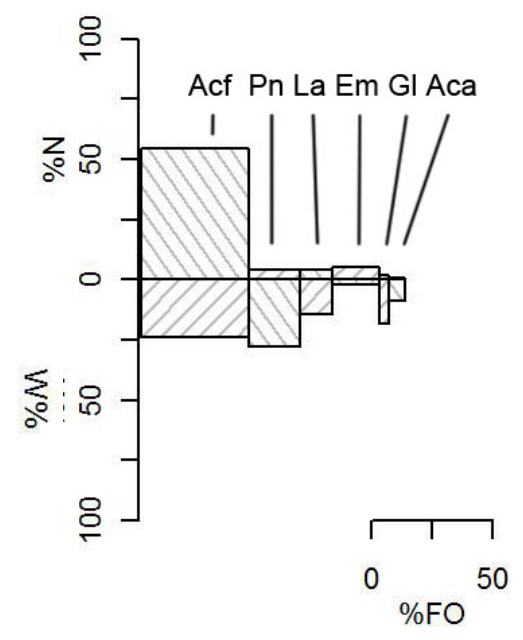

B. Torok, non-pupping

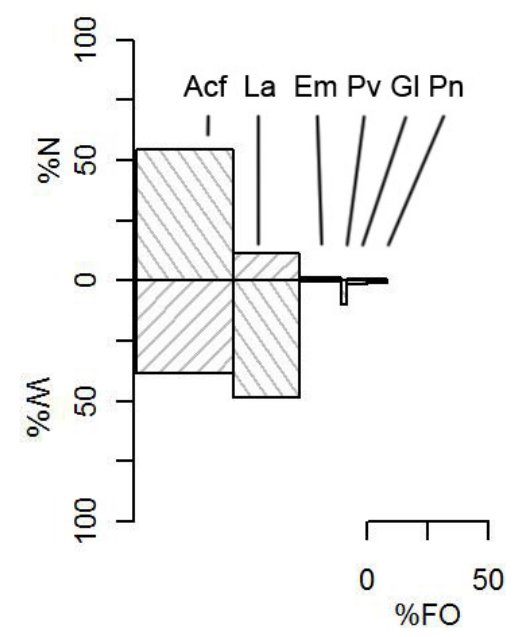

C. Torok, pupping

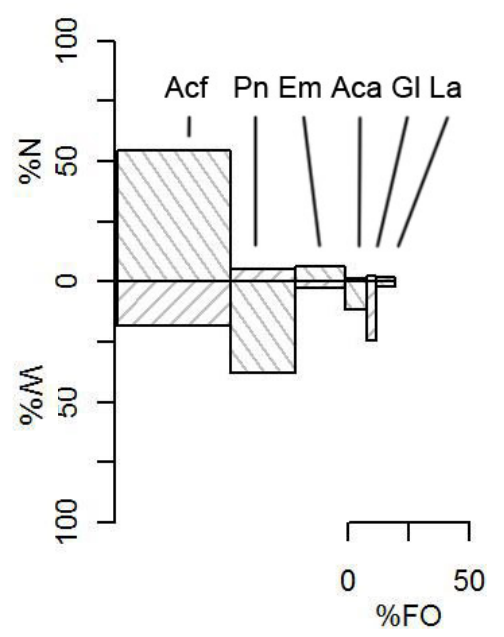

Figure 6. Index of Relative Importance (IRI) of harbor seal diet (1991/1992; Torok 1994); data from all sampled locations (almost exclusively south bay locations) during all seasons (A), for data from all sampled locations during non-pupping season (B), and all sampled locations during pupping season $(\mathrm{C})$; where, Aca $=$ Jacksmelt, Acf $=$ Yellowfin Goby, Em = Northern Anchovy, Gl = White Croaker, La = Staghorn Sculpin, $\mathrm{Pn}=$ Plainfin Midshipman. 


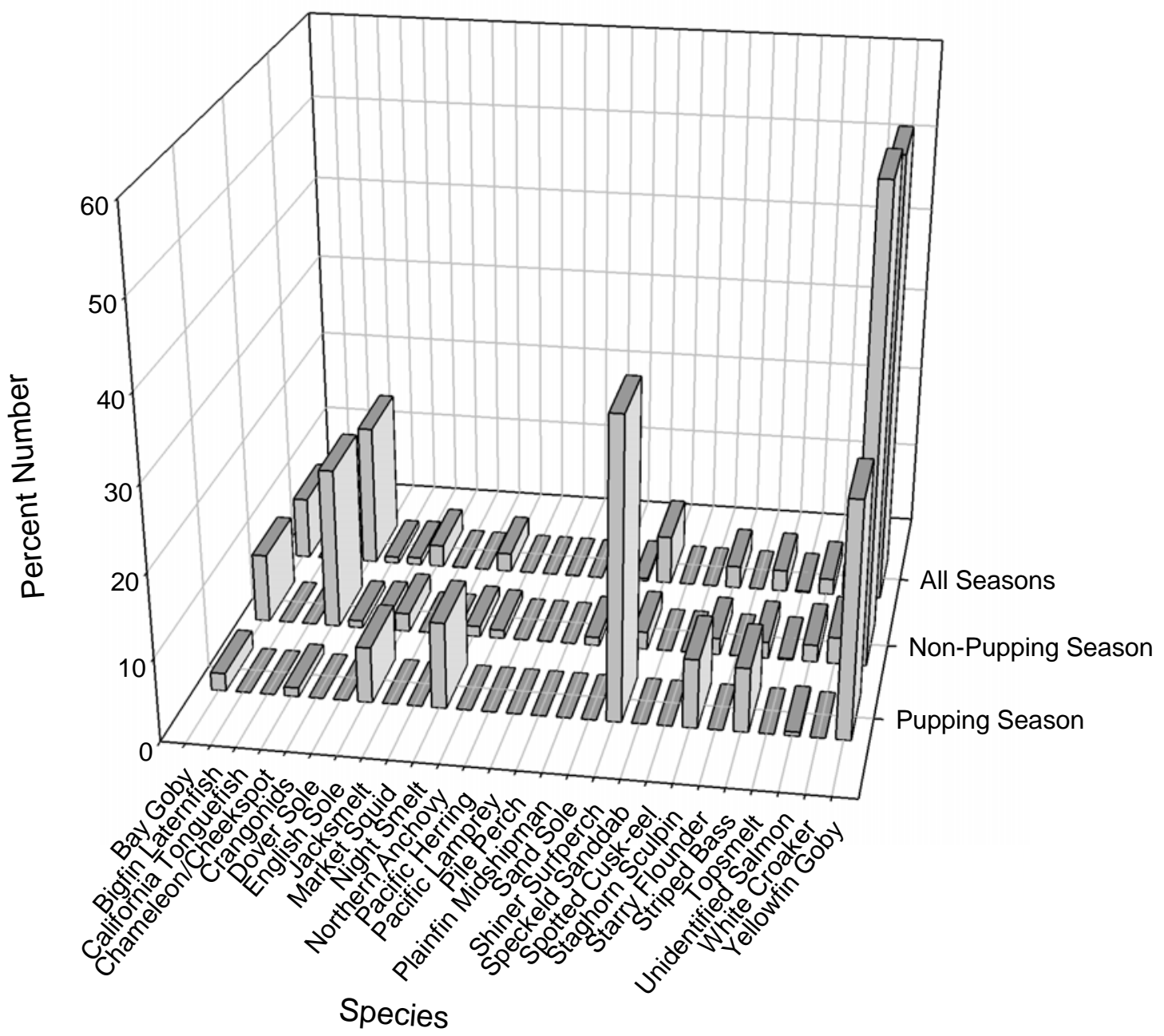

Figure 7: Percent number $(\% \mathrm{~N})$ of prey species by season for harbor seal fecal samples from July 2007- July 2008. Species are listed alphabetically. 


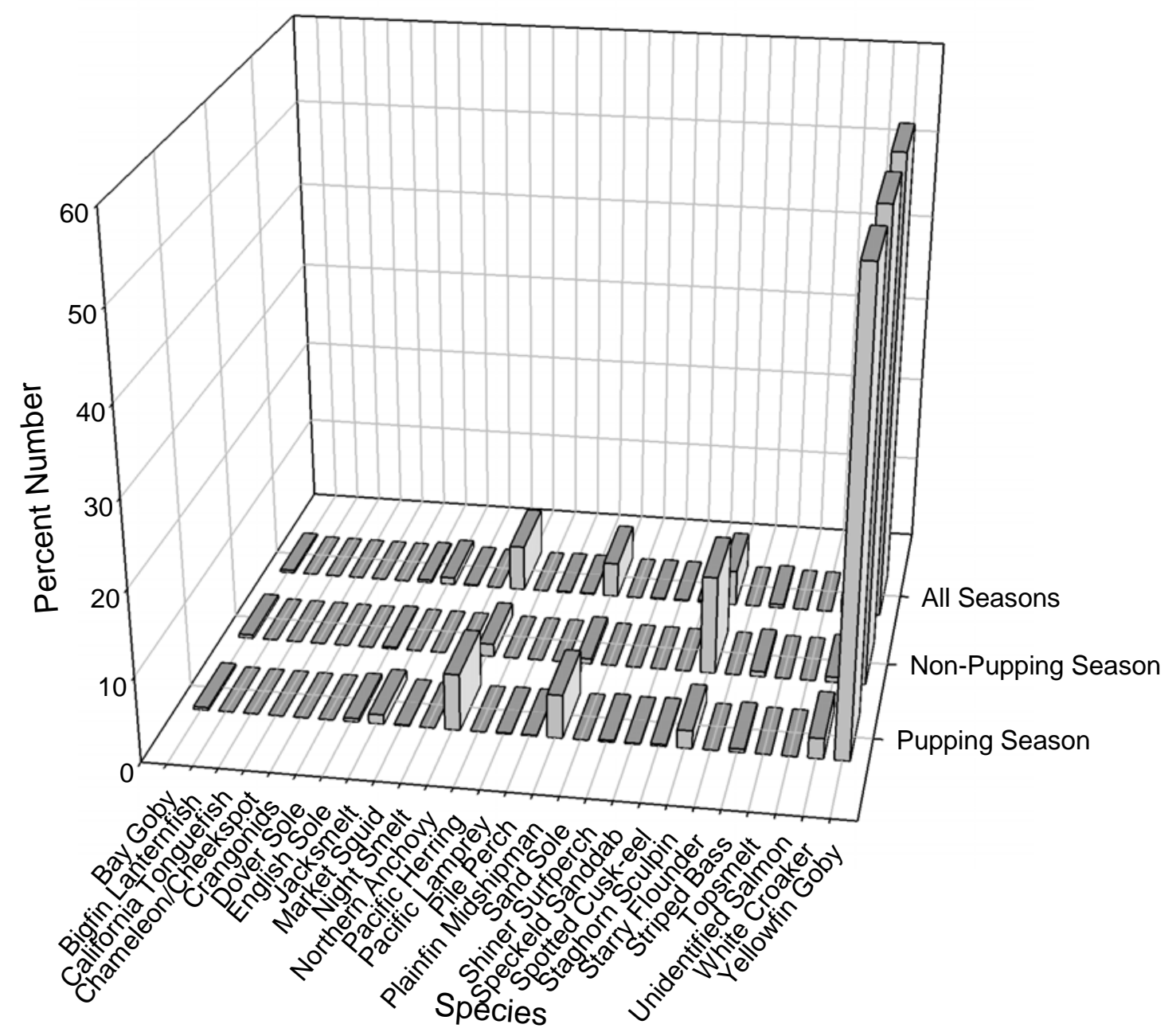

Figure 8: Percent number $(\% \mathrm{~N})$ of prey species per season for harbor seals from February 1991- January 1992 (Torok 1994). Species are listed alphabetically. 
Prey importance in the diet varied by season and location, as predicted by hypothesis 5. When SFB was separated into locations (NSFB and SSFB), the IRI changed significantly numerically (Tables 3, 4, 5), visually using IRI diagrams (Figs. 9, 10), and graphically (Figs. 5, 11). The most important species from SFB during all seasons were: Yellowfin Goby, Northern Anchovy, Chameleon/Cheekspot Goby, Bay Goby, Plainfin Midshipman, and Staghorn Sculpin (Leptocottus armatus). In NSFB, during pupping season the diet was less varied and Northern Anchovy became more important. During the non-pupping season in NSFB the diet was more varied. Northern Anchovy, Plainfin Midshipman and Yellowfin Goby were the most important prey items at this time. Conversely, in SSFB the diet became more varied during pupping season, which was not expected. At this time, Yellowfin Goby was the most important food item in the diet, followed by Cheekspot/Chameleon Goby. However, in SSFB during the pupping season, Shiner Surfperch and Yellowfin Goby were the most important food items in the diet followed by Northern Anchovy. These findings support hypothesis 5, that harbor seal diet would vary by location. SRCs indicated that the diet of harbor seals in NSFB was significantly different than the diet of those in SSFB $(\mathrm{P}>0.05)$, confirming hypothesis 5. 
Table 4. Diet composition of harbor seals for SFB during pupping and non-pupping seasons based on analysis of fecal samples $(\mathrm{n}=266)$ collected in San Francisco Bay, California.

\begin{tabular}{|c|c|c|c|c|c|c|c|c|c|c|c|c|}
\hline \multirow[t]{2}{*}{ Prey } & \multicolumn{4}{|c|}{ Pupping Season } & \multicolumn{4}{|c|}{ Non-pupping Season } & \multicolumn{4}{|c|}{ Combined } \\
\hline & $\% \mathrm{M}$ & $\% \mathrm{~N}$ & $\% \mathrm{FO}$ & \%IRI & $\% \mathrm{M}$ & $\% \mathrm{~N}$ & $\% \mathrm{FO}$ & \%IRI & $\% \mathrm{M}$ & $\% \mathrm{~N}$ & $\% \mathrm{FO}$ & $\%$ \%RI \\
\hline Acf & 9.9 & 8.1 & 16.0 & 287.7 & 40.6 & 37.9 & 48.6 & 3813.4 & 33.6 & 31.2 & 41.3 & 2673.2 \\
\hline Em & 50.6 & 53.1 & 58.0 & 6015.8 & 15.4 & 16.2 & 19.1 & 603.5 & 23.3 & 24.5 & 27.8 & 1329.0 \\
\hline $\mathrm{Tt} / \mathrm{Ig}$ & 1.7 & 1.4 & 4.0 & 12.3 & 10.5 & 12.3 & 19.7 & 448.6 & 8.7 & 9.9 & 16.1 & 299.7 \\
\hline Lel & 1.8 & 1.9 & 10.0 & 36.6 & 4.8 & 5.6 & 23.7 & 246.7 & 4.1 & 4.8 & 20.6 & 183.5 \\
\hline $\mathrm{La}$ & 4.7 & 6.6 & 10.0 & 113.2 & 4.9 & 5.1 & 8.1 & 80.6 & 4.8 & 5.4 & 8.5 & 87.5 \\
\hline $\mathrm{Pn}$ & 3.5 & 2.4 & 8.0 & 47.0 & 5.6 & 5.3 & 9.8 & 106.5 & 5.1 & 4.6 & 9.4 & 91.6 \\
\hline Crang & $\mathrm{N} / \mathrm{A}$ & 4.6 & 5.9 & 27.1 & $\mathrm{~N} / \mathrm{A}$ & 4.1 & 4.9 & 19.9 & N/A & 6.4 & 9.6 & 61.5 \\
\hline Gl & 2.0 & 2.0 & 2.0 & 8.0 & 5.8 & 4.9 & 6.4 & 68.0 & 4.9 & 4.3 & 5.4 & 49.5 \\
\hline $\mathrm{Ca}$ & 9.9 & 9.9 & 12.0 & 237.5 & 3.1 & 3.3 & 5.6 & 35.9 & 4.1 & 4.2 & 5.8 & 48.8 \\
\hline Msa & 8.8 & 8.7 & 12.0 & 210.4 & 2.0 & 2.1 & 2.9 & 11.7 & 3.5 & 3.6 & 4.9 & 34.9 \\
\hline $\mathrm{Pv}$ & 1.6 & 2.1 & 4.0 & 15.1 & 2.2 & 2.4 & 5.8 & 26.9 & 2.1 & 2.4 & 5.4 & 24.0 \\
\hline $\mathrm{Pm}$ & 0.2 & 0.1 & 2.0 & 0.6 & 2.2 & 2.2 & 6.4 & 27.7 & 1.7 & 1.7 & 5.4 & 18.5 \\
\hline Aca & 2.5 & 2.0 & 4.0 & 18.2 & 0.3 & 0.3 & 1.2 & 0.6 & 0.8 & 0.7 & 1.8 & 2.6 \\
\hline St & 0.0 & 0.0 & 0.0 & 0.0 & 1.2 & 1.2 & 1.2 & 2.7 & 0.9 & 0.9 & 0.9 & 1.6 \\
\hline Chp & 1.2 & 0.4 & 4.0 & 6.6 & 0.1 & 0.1 & 1.2 & 0.2 & 0.4 & 0.1 & 1.8 & 1.0 \\
\hline $\mathrm{Ct}$ & 0.0 & 0.0 & 0.0 & 0.0 & 0.0 & 0.0 & 0.6 & 0.0 & 0.1 & 0.0 & 0.4 & 0.1 \\
\hline Ps & 1.5 & 1.3 & 2.0 & 5.6 & 0.2 & 0.0 & 0.6 & 0.1 & 0.5 & 0.3 & 0.9 & 0.7 \\
\hline Sal & $\mathrm{N} / \mathrm{A}$ & 3.5 & 11.4 & 39.9 & $\mathrm{~N} / \mathrm{A}$ & 4.4 & 13.5 & 60.1 & $\mathrm{~N} / \mathrm{A}$ & 0.2 & 3.8 & 0.6 \\
\hline Mpa & 0.0 & 0.0 & 0.0 & 0.0 & 0.6 & 0.6 & 0.6 & 0.7 & 0.4 & 0.4 & 0.4 & 0.4 \\
\hline Syc & 0.0 & 0.0 & 0.0 & 0.0 & 0.6 & 0.6 & 0.6 & 0.7 & 0.4 & 0.4 & 0.4 & 0.4 \\
\hline $\mathrm{Aa}$ & 0.0 & 0.0 & 0.0 & 0.0 & 0.1 & 0.3 & 1.2 & 0.5 & 0.1 & 0.2 & 0.9 & 0.3 \\
\hline Sat & 0.0 & 0.0 & 0.0 & 0.0 & 0.6 & 0.4 & 0.6 & 0.6 & 0.4 & 0.3 & 0.4 & 0.3 \\
\hline Cst & 0.0 & 0.0 & 0.0 & 0.0 & 0.0 & 0.0 & 0.0 & 0.0 & 0.0 & 0.0 & 0.0 & 0.0 \\
\hline $\mathrm{Rv}$ & 0.0 & 0.0 & 0.0 & 0.0 & 0.0 & 0.0 & 0.0 & 0.0 & 0.0 & 0.0 & 0.0 & 0.0 \\
\hline $\mathrm{Lt}$ & N/A & 0.1 & 1.7 & 0.1 & N/A & 0.1 & 2.2 & 0.2 & 0.0 & 0.0 & 0.0 & 0.0 \\
\hline Do & 0.0 & 0.0 & 0.0 & 0.0 & 0.0 & 0.0 & 0.0 & 0.0 & 0.0 & 0.0 & 0.0 & 0.0 \\
\hline
\end{tabular}

Each prey item is represented using percent mass $(\% \mathrm{M})$, percent number $(\% \mathrm{~N})$, percent frequency of occurrence $(\% \mathrm{FO})$, and index of relative importance $(\% \mathrm{IRI})$. Data are ranked high to low according to \%IRI for combined seasons. Refer to Table 1 for names of species. Prey species are listed in order of IRI magnitude. 
Table 5. Diet composition of harbor seals for NSFB haul-out locations (Yerba Buena Island and Castro Rocks) during pupping and non-pupping seasons based on analysis of fecal samples ( $\mathrm{n}=107)$ collected in San Francisco Bay, California, from June 2007 to July 2008.

\begin{tabular}{|c|c|c|c|c|c|c|c|c|c|c|c|c|}
\hline \multirow[t]{2}{*}{ Prey } & \multicolumn{4}{|c|}{ Pupping Season } & \multicolumn{4}{|c|}{ Non-pupping Season } & \multicolumn{4}{|c|}{ Combined } \\
\hline & $\% \mathrm{M}$ & $\% \mathrm{~N}$ & $\% \mathrm{FO}$ & IRI & $\% \mathrm{M}$ & $\% \mathrm{~N}$ & $\% \mathrm{FO}$ & IRI & $\% \mathrm{M}$ & $\% \mathrm{~N}$ & $\% \mathrm{FO}$ & $\overline{I R I}$ \\
\hline Em & 65.5 & 68.2 & 73.0 & 9752.6 & 36.0 & 37.7 & 43.7 & 3217.1 & 46.5 & 48.6 & 54.2 & 5155.3 \\
\hline $\mathrm{Pn}$ & 4.7 & 3.2 & 10.8 & 85.7 & 12.2 & 11.4 & 22.5 & 531.7 & 9.7 & 8.7 & 18.7 & 343.9 \\
\hline Acf & 1.0 & 1.0 & 8.1 & 16.1 & 12.8 & 11.6 & 21.1 & 515.7 & 7.9 & 7.1 & 15.9 & 238.7 \\
\hline $\mathrm{La}$ & 6.1 & 6.0 & 8.1 & 98.2 & 9.0 & 9.6 & 14.1 & 261.1 & 8.0 & 8.4 & 12.1 & 200.3 \\
\hline Crang & $\mathrm{N} / \mathrm{A}$ & 8.3 & 12.5 & 104.0 & $\mathrm{~N} / \mathrm{A}$ & 8.7 & 9.1 & 78.8 & $\mathrm{~N} / \mathrm{A}$ & 8.3 & 10.0 & 83.4 \\
\hline Gl & 2.7 & 2.7 & 2.7 & 14.6 & 9.0 & 7.4 & 9.9 & 161.4 & 6.0 & 4.9 & 6.5 & 71.1 \\
\hline Msa & 9.2 & 9.1 & 13.5 & 247.1 & 2.0 & 2.3 & 4.2 & 17.8 & 4.5 & 4.6 & 7.5 & 68.2 \\
\hline Sal & N/A & 2.6 & 5.0 & 12.8 & N/A & 6.5 & 18.2 & 119.1 & N/A & 5.1 & 13.3 & 67.4 \\
\hline Pm & 0.2 & 0.2 & 2.7 & 1.1 & 4.4 & 4.9 & 8.5 & 78.4 & 3.0 & 3.3 & 6.5 & 41.2 \\
\hline Lel & 1.6 & 1.8 & 10.8 & 36.6 & 1.5 & 1.7 & 5.6 & 18.5 & 1.6 & 1.8 & 7.5 & 25.0 \\
\hline $\mathrm{Ca}$ & 0.0 & 0.8 & 2.7 & 2.2 & 3.1 & 3.3 & 5.6 & 35.9 & 2.0 & 2.5 & 4.7 & 21.1 \\
\hline $\mathrm{Pv}$ & 0.5 & 0.6 & 2.7 & 3.0 & 3.3 & 2.8 & 5.6 & 34.5 & 2.4 & 2.0 & 4.7 & 20.8 \\
\hline $\mathrm{Tt} / \mathrm{Ig}$ & 1.3 & 1.5 & 2.7 & 7.5 & 1.8 & 2.2 & 4.2 & 17.1 & 1.7 & 2.0 & 3.7 & 13.6 \\
\hline Aca & 3.4 & 2.8 & 5.4 & 33.2 & 0.3 & 0.6 & 1.4 & 1.2 & 1.4 & 1.3 & 2.8 & 7.6 \\
\hline St & 0.0 & 0.0 & 0.0 & 0.0 & 1.4 & 1.4 & 1.4 & 4.0 & 1.9 & 1.9 & 1.9 & 7.0 \\
\hline Chp & 1.7 & 0.5 & 5.4 & 12.0 & 0.3 & 0.2 & 2.8 & 1.4 & 0.8 & 0.3 & 3.7 & 4.1 \\
\hline Syc & 0.0 & 0.0 & 0.0 & 0.0 & 1.4 & 1.4 & 1.4 & 4.0 & 0.9 & 0.9 & 0.9 & 1.7 \\
\hline Sat & 0.0 & 0.0 & 0.0 & 0.0 & 1.4 & 1.0 & 1.4 & 3.4 & 0.9 & 0.7 & 0.9 & 1.5 \\
\hline Ps & 2.1 & 1.7 & 2.7 & 10.2 & 0.0 & 0.0 & 0.0 & 0.0 & 0.7 & 0.6 & 0.9 & 1.2 \\
\hline $\mathrm{Aa}$ & 0.0 & 0.0 & 0.0 & 0.0 & 0.1 & 0.5 & 1.4 & 0.9 & 0.1 & 0.3 & 0.9 & 0.4 \\
\hline $\mathrm{Lt}$ & N/A & 0.0 & 0.0 & 0.0 & N/A & 0.2 & 3.9 & 0.9 & N/A & 0.2 & 2.5 & 0.4 \\
\hline $\mathrm{Ct}$ & 0.0 & 0.0 & 0.0 & 0.0 & 0.0 & 0.1 & 1.4 & 0.2 & 0.2 & 0.1 & 0.9 & 0.2 \\
\hline Cst & 0.0 & 0.0 & 0.0 & 0.0 & 0.0 & 0.0 & 0.0 & 0.0 & 0.0 & 0.0 & 0.0 & 0.0 \\
\hline Do & 0.0 & 0.0 & 0.0 & 0.0 & 0.0 & 0.0 & 0.0 & 0.0 & 0.0 & 0.0 & 0.0 & 0.0 \\
\hline Mpa & 0.0 & 0.0 & 0.0 & 0.0 & 0.0 & 0.0 & 0.0 & 0.0 & 0.0 & 0.0 & 0.0 & 0.0 \\
\hline $\mathrm{Rv}$ & 0.0 & 0.0 & 0.0 & 0.0 & 0.0 & 0.0 & 0.0 & 0.0 & 0.0 & 0.0 & 0.0 & 0.0 \\
\hline
\end{tabular}

Each prey item is presented in percent mass $(\% \mathrm{M})$, percent number $(\% \mathrm{~N})$, percent

frequency of occurrence $(\% \mathrm{FO})$, and index of relative importance $(\% \mathrm{IRI})$. Data are ranked high to low according to \%IRI for combined seasons. Refer to Table 1 for names of species. Prey species are listed in order of IRI magnitude. 

A. SFB, all seasons
B. SFB, non-pupping
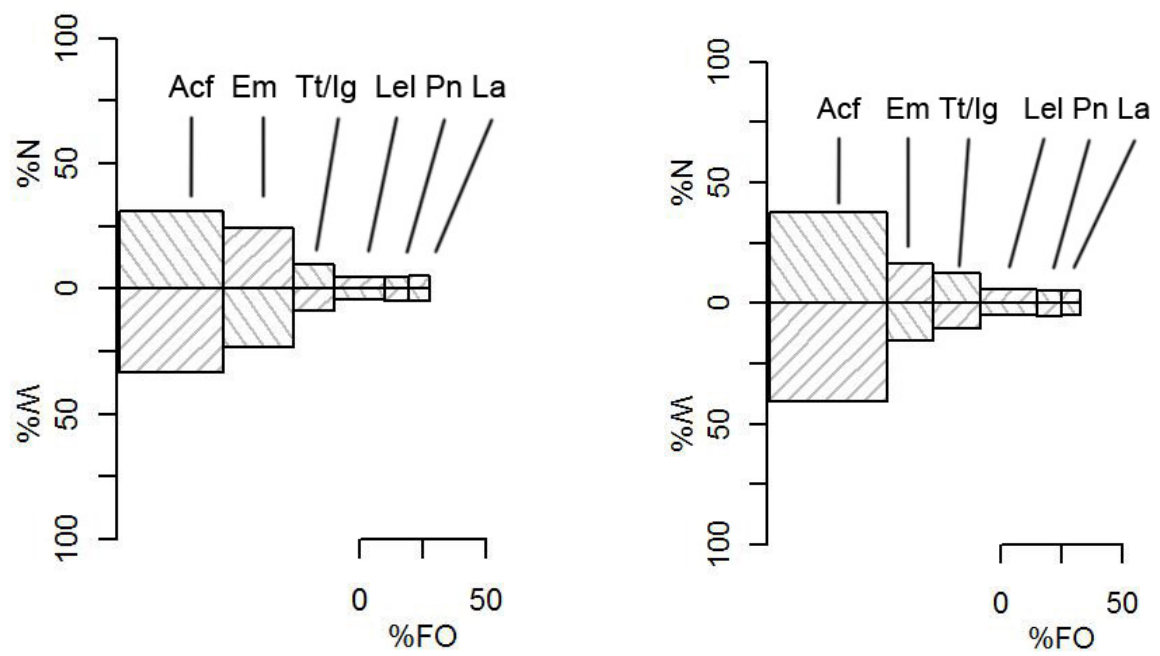

C. SFB, pupping

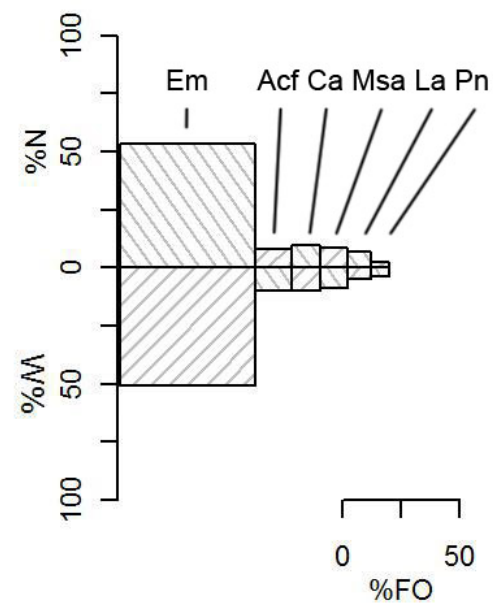

Figure 9. Index of Relative Importance (IRI) of harbor seal diets (2007/2008); data from all sampled locations during all seasons from July 2007- July 2008 (A), for data from all sampled locations during non-pupping season (B), and all sampled locations during pupping season $(\mathrm{C})$; where Acf $=$ Yellowfin Goby, $\mathrm{Ca}=$ Shiner Surfperch, $\mathrm{Em}=$ Northern Anchovy, La = Staghorn Sculpin, Lel = Bay Goby, Msa = Striped Bass, Pn = Plainfin Midshipman, Tt/Ig = Chameleon/Cheekspot Goby. 
A. NSFB, all seasons

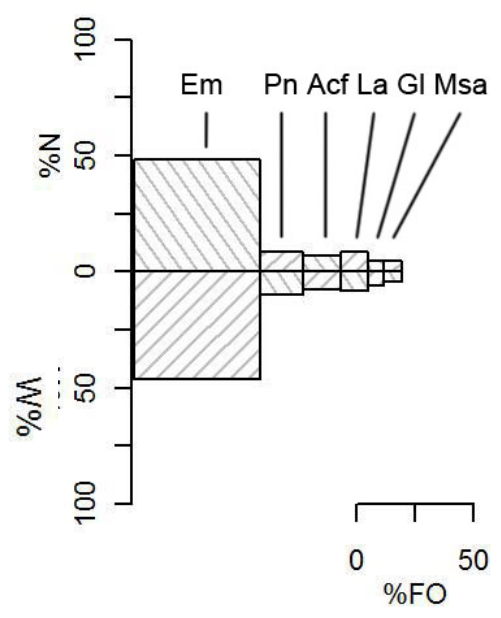

B. NSFB, non-pupping

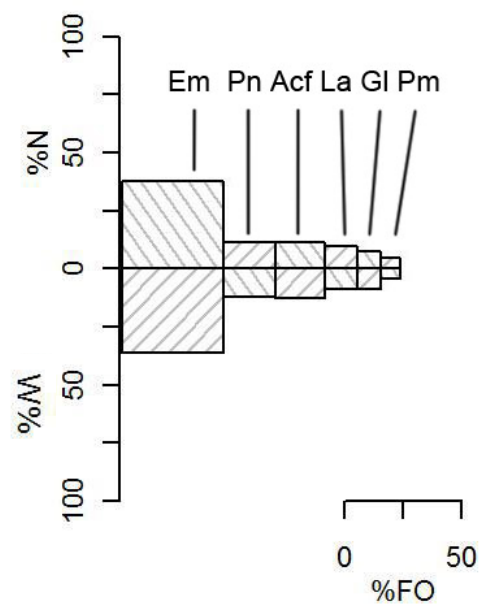

C. NSFB, pupping

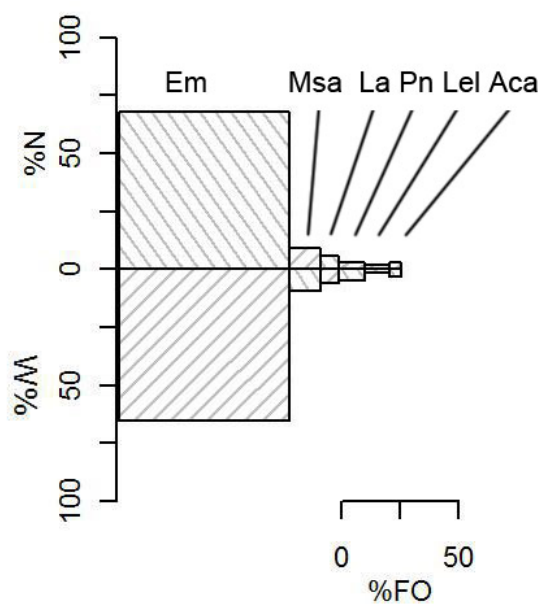

Figure 10. Index of Relative Importance (IRI) of harbor seal diets (2007/2008); data from all North Bay locations during all seasons from July 2007 - July 2008 (A), for data from all North Bay locations during non-pupping season (B), and all North Bay locations during pupping Season $(\mathrm{C})$; where, Aca $=$ Jacksmelt, Acf = Yellowfin Goby, Em = Northern Anchovy, Gl = White Croaker, $\mathrm{La}=$ Staghorn Sculpin, Lel = Bay Goby, Msa = Striped Bass, $\mathrm{Pm}=$ Sand Sole, $\mathrm{Pn}=$ Plainfin Midshipman . 


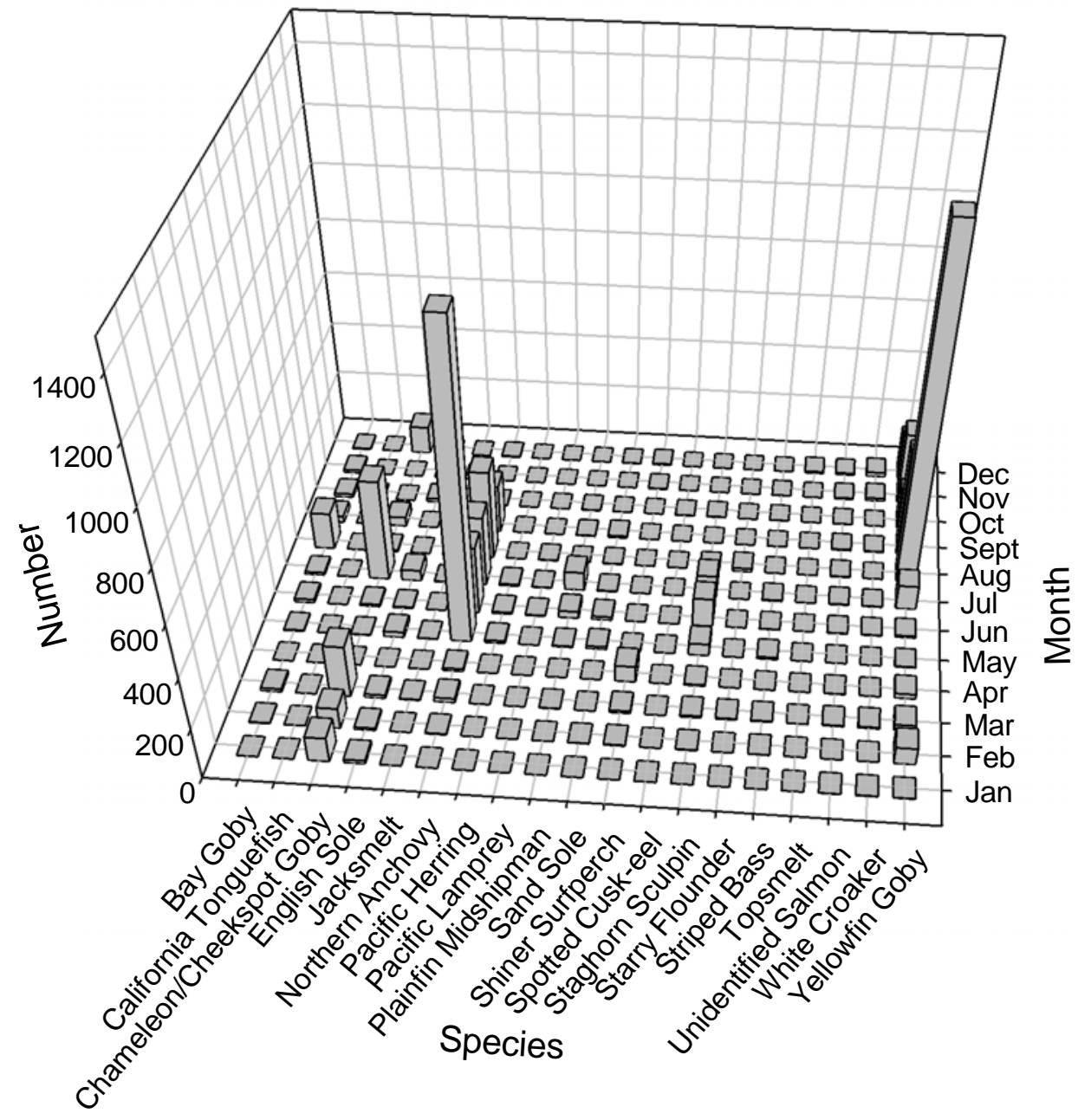

Figure 11: Number of each species per month for fecal analysis, July 2007 until July 2008. Species are listed alphabetically. 
The diet of harbor seals also varied by season; but only when separated by location. SRCs indicated that the diet of harbor seals for SFB was not significantly different during pupping and non-pupping seasons $(\mathrm{P}<0.05)$, however, diet in NSFB and in SSFB was significantly different between pupping and non-pupping seasons $(\mathrm{P}>$ 0.05), indicating that combining all data for all locations has a tendency to misrepresent location specific diet.

The most dominant species during the pupping season for SFB was Northern Anchovy, and to a lesser extent, Yellowfin Goby, Shiner Surfperch (Cymatogaster aggregata), Striped Bass (Morone saxatilis) and Staghorn Sculpin (Table 4 Figure 9). Prey importance during the non-pupping season was more varied and more evenly distributed. The most important species for SFB during non-pupping season were Yellowfin Goby, and less important were Northern Anchovy, Chameleon/Cheekspot goby, Bay Goby, Plainfin Midshipman, Staghorn Sculpin, and White Croaker (Genyonemus lineatus) (Table 4, Figure 9).

Pronounced seasonal changes in diet were observed at different locations (NSFB and SSFB). The tendency for a more varied diet during the non-pupping season, and a more restricted diet during the pupping season occurred at both locations (NSFB and SSFB; Tables 3, 4, 5 Figs. 5, 9, 10). For NSFB during pupping season the most important species was Northern Anchovy (Table 5, Fig. 10). During the non-pupping season, Northern Anchovy still dominated the diet; however, other species were greater in importance, such as Plainfin Midshipman, Yellowfin Goby, Staghorn Sculpin, and White Croaker (Table 5, Fig. 10). During the pupping season in SSFB, Shiner Surfperch 
and Yellowfin Goby were dominant (Table 3, Fig. 5). These two species comprised the majority of prey, followed by Northern Anchovy and Staghorn Sculpin (Table 3, Fig. 5).

During the non-pupping season in SSFB the diet was more diverse, the dominant species being Yellowfin Goby, Chameleon/Cheekspot Goby, and Bay Goby (Table 3, Fig. 5)

These findings support hypothesis 4 , that there would be a change in diet during the nonpupping and pupping seasons.

When RB and IRIs were compared for SFB, NSFB, and SSFB, estimates for RB (Tables 6, 7, 8) indicated some similarities with IRI results and reinforced the importance of certain prey in the diet. These metrics are compared relative to each other, with neither being a more important measure than the other. The prey species that ranked the greatest using RB were within the top six most important prey items using IRI. However, there were some differences between the two metrics. In SFB during all seasons (nonpupping and pupping) and during the pupping season, the dietary importance of Shiner Surfperch was overestimated by the RB method as compared to IRI, and Yellowfin Goby was underestimated by the RB method relative to IRI (Table 6). For all seasons in SSFB during pupping season, Shiner Surfperch was overestimated by the RB method as compared to IRI and Yellowfin Goby was underestimated by the RB method (Table 7). For all seasons in NSFB, Staghorn Sculpin was overestimated by the RB method, whereas in the pupping season, Staghorn Sculpin and Starry Flounder were overestimated by the RB method (Table 8 ). 
Table 6. Reconstructed Biomass Model (RBM) of consumption by harbor seals in San Francisco Bay, California for SFB.

\begin{tabular}{lrrr}
\hline \hline Species & Pupping Season & Non-Pupping Season & Combined Seasons \\
\hline Shiner Surfperch & 95.33 & 0.42 & 80.06 \\
Yellowfin Goby & 0.18 & 55.00 & 9.00 \\
Northern Anchovy & 2.34 & 10.59 & 3.67 \\
Staghorn Sculpin & 0.22 & 13.27 & 2.32 \\
Plainfin Midshipman & 0.01 & 5.68 & 0.92 \\
White Croaker & 0.03 & 5.54 & 0.92 \\
Striped Bass & 0.89 & 0.25 & 0.79 \\
English Sole & 0.04 & 2.80 & 0.48 \\
Bay Goby & 0.03 & 2.56 & 0.43 \\
Starry Flounder & 0.49 & 0.11 & 0.43 \\
Chameleon/Cheekspot Goby & 0.03 & 2.41 & 0.41 \\
Pacific Herring & 0.25 & 0.14 & 0.23 \\
Jacksmelt & 0.15 & 0.05 & 0.13 \\
Sand Sole & 0.01 & 0.60 & 0.10 \\
Dover Sole & N/A & 0.16 & 0.03 \\
California Tonguefish & N/A & 0.15 & 0.02 \\
Topsmelt & N/A & 0.10 & 0.02 \\
Spotted Cusk-eel & N/A & 0.10 & 0.02 \\
Night Smelt & N/A & 0.06 & 0.01 \\
Bigfin Lanternfish & N/A & 0.01 & 0.00 \\
\hline R & & &
\end{tabular}

Results are ranked high to low according to combined seasons. Units are the proportion of the total biomass consumed. 
Table 7. RBM of consumption by harbor seals in San Francisco Bay, California for SSFB haul-out sites (Corkscrew Slough, Mowry Slough, Bair Island).

\begin{tabular}{lrrr}
\hline \hline Species & & & \\
\hline Shiner Surfperch & Pupping Season & Non-Pupping Season & Combined Sea sons \\
Yellowfin Goby & 99.82 & 0.38 & 89.11 \\
Northern Anchovy & 0.14 & 88.77 & 9.69 \\
Staghorn Sculpin & 0.02 & 0.20 & 0.04 \\
Plainfin Midshipman & 0.00 & 0.01 & 0.00 \\
White Croaker & N/A & 0.04 & 0.00 \\
Striped Bass & N/A & 1.46 & 0.16 \\
English Sole & 0.01 & 0.23 & 0.03 \\
Bay Goby & 0.00 & 0.30 & 0.03 \\
Starry Founder & 0.00 & 3.94 & 0.43 \\
Chameleon/Cheekspot Goby & N/A & 0.18 & 0.02 \\
Pacific Herring & 0.00 & 3.98 & 0.43 \\
Jacksmelt & N/A & N/A & N/A \\
Sand Sole & N/A & 0.07 & 0.01 \\
Dover Sole & N/A & 0.05 & 0.01 \\
California Tonguefish & N/A & 0.27 & 0.03 \\
Topsmelt & N/A & N/A & N/A \\
Spotted Cusk-eel & N/A & 0.11 & 0.02 \\
Night Smelt & N/A & N/A & N/A \\
Bigfin Lanternfish & N/A & N/A & N/A \\
\hline
\end{tabular}

Results are ranked high to low according to combined seasons. Units are of proportion of the total biomass consumed. 
Table 8. RBM for consumption by harbor seals in San Francisco Bay, California, for NSFB locations (Yerba Buena Island, Castro Rocks).

\begin{tabular}{lrrr}
\hline \hline Species & Pupping Season & Non-Pupping Season & Combined Seasons \\
\hline Northern Anchovy & 51.53 & 26.28 & 35.65 \\
Staghorn Sculpin & 4.91 & 33.29 & 22.76 \\
Plainfin Midshipman & 0.21 & 14.18 & 9.00 \\
White Croaker & 0.72 & 11.69 & 7.62 \\
Striped Bass & 19.60 & 0.29 & 7.45 \\
English Sole & 0.86 & 6.59 & 4.46 \\
Starry Flounder & 10.97 & N/A & 4.07 \\
Yellowfin Goby & 0.91 & 4.01 & 2.86 \\
Pacific Herring & 5.58 & 0.36 & 2.29 \\
Jacksmelt & 3.34 & 0.02 & 1.25 \\
Sand Sole & 0.20 & 1.42 & 0.97 \\
Bay Goby & 0.54 & 0.48 & 0.50 \\
Shiner Surfperch & 0.01 & 0.47 & 0.30 \\
Chamleon/Cheekspot Goby & 0.61 & 0.04 & 0.25 \\
California Tonguefish & N/A & 0.37 & 0.23 \\
Spotted Cusk-eel & N/A & 0.24 & 0.15 \\
Night Smelt & N/A & 0.16 & 0.10 \\
Topsmelt & N/A & 0.08 & 0.05 \\
Bigfin Lanternfish & N/A & 0.02 & 0.01 \\
Dover Sole & N/A & N/A & N/A \\
\hline
\end{tabular}

Results are ranked high to low according to combined seasons. Units are the proportion of the total biomass consumed.

A SRC indicated the CDFG trawl data and harbor seal diet were significantly correlated $(\mathrm{P}<0.05)$. This confirmed hypothesis 2 that harbor seal diet would reflect the abundance and distribution of fishes within bay as determined by CDFG trawls. Graphical representation also depicts similarity with some visible differences in association occurring for the number of Plainfin Midshipman, Pacific Herring, Yellowfin Goby, and Chameleon/Cheekspot Goby (Fig. 14). Numbers of Plainfin Midshipman and 
Pacific Herring were greater in the trawls and less in the diet of harbor seals, whereas numbers of Yellowfin Goby and Chameleon/Cheekspot goby were greater in the diet but less in the trawls. The increases in Plainfin Midshipman and Pacific Herring were consistent with spawning activity (Fig. 12), whereas the increases in Yellowfin Goby and Chameleon/Cheekspot Goby were consistent with CDFG trawl sampling biases.

Since 1991-1992, there appear to have been increases in Chameleon Goby/Cheekspot Goby, and Yellowfin Goby, in both the trawls (Figs. 12, 13, 14), and corresponding increases in the diet (Figs. 14, 8, 9). In contrast, native species, such as Northern Anchovy and White Croaker, decreased (Fig. 14). This supports hypothesis 3 that there would be an increase in the diet in the number of invasive species with increase of non-native invasive fish species. 


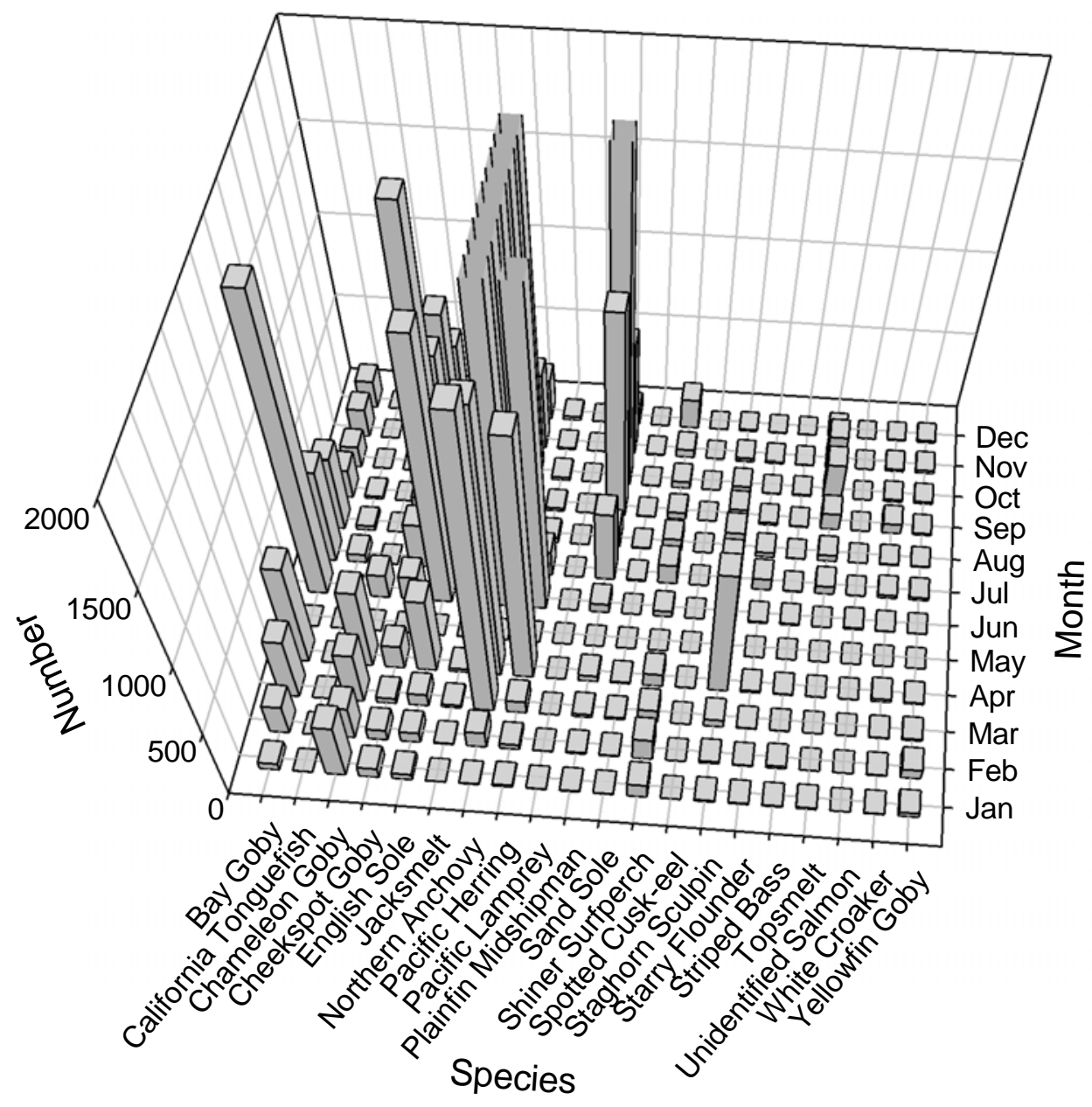

Figure 12. Number of species per month for trawl data (CDFG) from July 2007 until July 2008 for SFB; the number axis has been scaled down to show variation per month. The greatest number of fish for any month is Northern Anchovy in March at approximately 19,000 . 


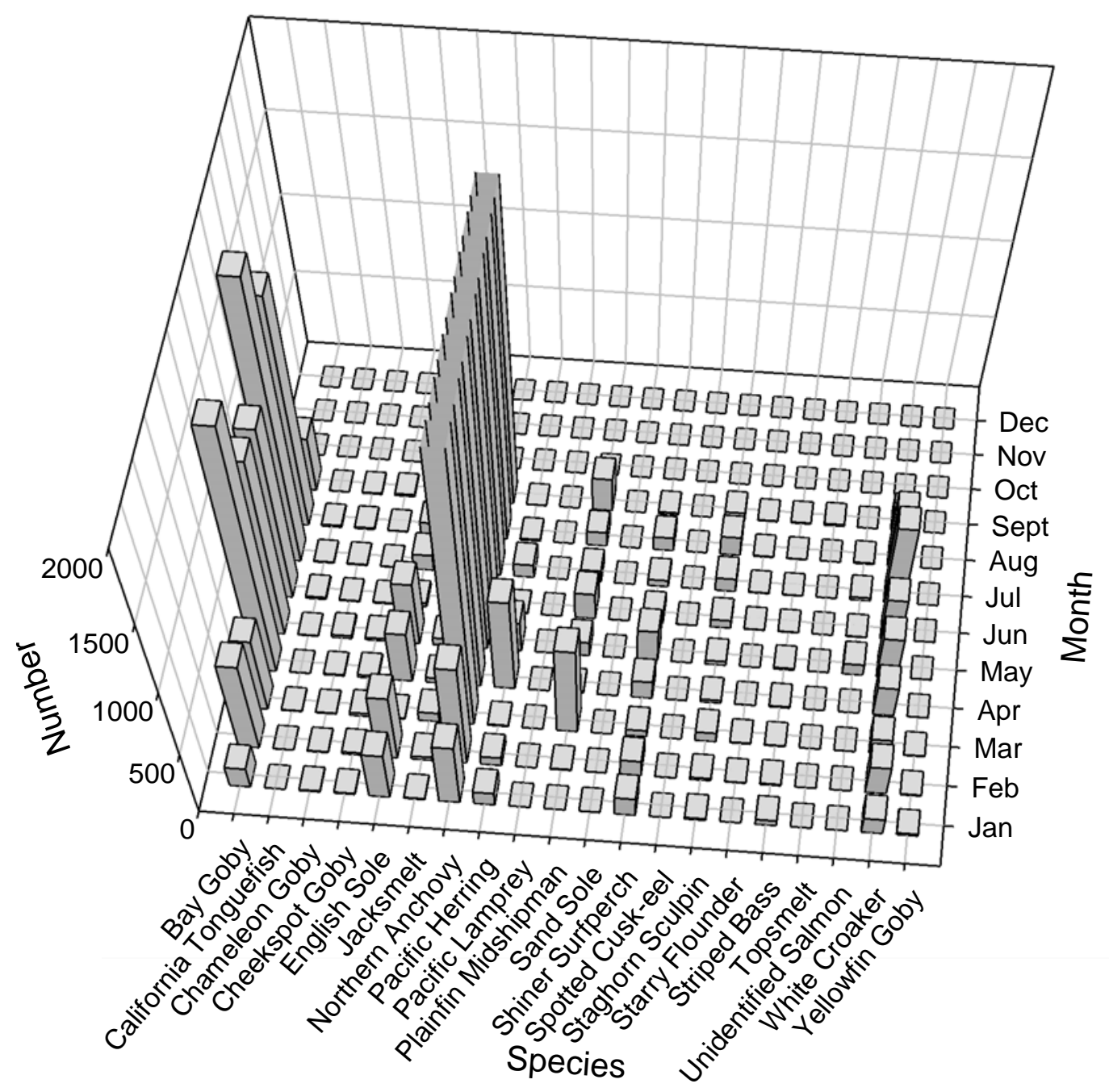

Figure 13: Number of species per month for California Department of Fish and Game data from February 1991 until January 1992; the number axis has been scaled down to show variation per month. The greatest number of fish for any month is Northern Anchovy in March at approximately 30,000. 

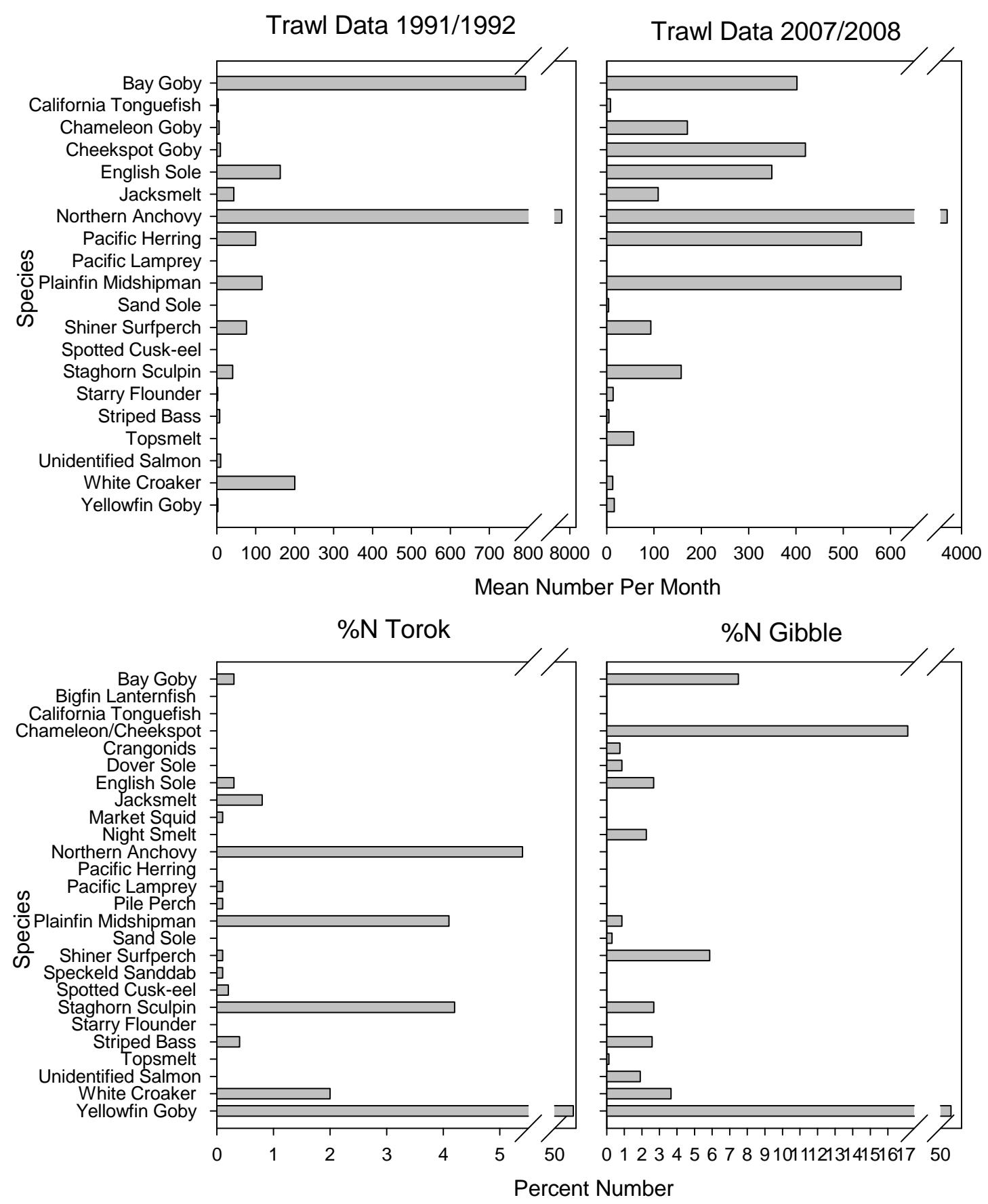

Figure 14: Mean number per month of fish caught in CDFG trawls from February 1991 to January 1992, and July 2007 to July 2008; and percent number of fish prey in harbor seal diet from February 1991 to January 1992, and from July 2007- July 2008 


\section{DISCUSSION}

Scat analysis, although well researched, is innately biased. These biases include non-uniform passage of hard parts and partial consumption of prey items. Non-uniform passage of hard parts may result in otolith size reduction and degradation and reduced recovery rates (Pitcher 1980, Da Silva and Neilson 1985, Jobling and Breiby 1986, Harvey 1987). Otolith degradation can skew prey identifications and size estimations, and recovery rate reduction may affect consumption estimates. Biases associated with otolith degradation and recovery rates can be minimized by applying correction factors (Harvey 1989, Phillips and Harvey 2009). Partial consumption of prey provides another source of bias. Large prey items are often partially consumed. If the heads, therefore otoliths, are not consumed, counting prey items using otoliths alone can be biased. This bias can be partially corrected using the all-structure technique. The all-structure technique uses all of the bony structures recovered in the samples to identify prey species (Olesiuk et al. 1990, Cottrell et al. 1996, Brown and Pierce 1998, Cottrell and Trites 2002, Phillips 2005). Historically only otoliths have been used for prey identification in scat analysis; the all-structure technique aids in identifying prey items previously not counted. This technique also aids in correcting for reduced recovery rates.

Top down effects by apex predators, such as harbor seals, are important for determining community structure (Hariston et al. 1960, Paine 1966, Fretwell 1987, Wootton et al. 1996). A change in predator density in any ecosystem can result in large scale variations to the food web, and can impact ecosystem heath (Fretwell 1977, 1987). Because of their influence on fish populations, understanding the diet of predators is 
essential to evaluate the ecosystems in which they live. Harbor seals unequivocally impact the ecosystem of SFB. Currently they are making positive impacts by consuming large quantities of non-native invasive fish species.

The diet of harbor seals in SFB has clearly changed since last studied by Torok (1994). The number of scats containing identifiable prey hard parts decreased from $71.2 \%$ reported by Torok (1994) in 1991-1992, to $53.6 \%$ found in my study from 2007 to 2008. A decrease in prey contained in each scat may be suggestive of a decrease in available prey. Because harbor seals are generalists, a decrease in prey contained per scat may equate to less prey per meal. Less prey per meal may indicate a decrease in readily available prey species.

Salmon in the genus Oncorhynchus were discovered in the diet in this study and were not seen in the diet of harbor seal during Torok's study. This is most likely explained by a difference in technique. Torok (1994) examined otoliths and beaks exclusively, whereas I used the all structures technique. If this technique had not been used during this study, these species would not have been identified, and would have gone unnoticed.

Non-native invasive species became more important in the diet of seals with time. Yellowfin Goby were dominant in both time periods (Tables 1, 4, Figures 5, 10); however, another non-native invasive species appeared in the diet of harbor seals in 2007 and 2008. Chameleon/Cheekspot was found in the diet in both NSFB and SSFB. This is the first time Cheekspot or Chameleon Gobies have been documented in the diet of 
harbor seals in SFB. The Chameleon/Cheekspot Gobies occurred in 17.1\% of scats for SSFB, and approximately $2 \%$ of scats in NSFB (Tables 3, 4, 5).

Yellowfin Goby and Chameleon Goby are native to estuarine Asiatic waters (Brittan et al. 1963), and were most likely introduced via ballast water from cargo ships in the 1960s (Brittan et al. 1963). Two new species of Asiatic gobies: the Shimofuri Goby (Tridentiger bifasciatus) and the Shokihaze Goby (Tridentiger barbatus) recently have appeared in CDFG trawls (CDFG, unpublished data), but have not yet been found in the diet of harbor seals within the bay. The increase of non-native invasive species in the diet of harbor seals is similar to the increases of non-native invasive species in the bay ecosystem (TBIES 2003, 2005), and may be indicative of ecosystem degradation.

Yellowfin and Chameleon Gobies use shallow mud flats, shallow bays, and small crevices (Herald and Eschmeyer 1983, Workman and Merz 2007). SSFB hosts optimal conditions for this species, and these gobies may be thriving and out-competing native species in the bay (Workman and Merz 2007). Gobies flourish in suboptimal habitats, and often have flexible generalist diets (Workman and Merz 2007, Utne-Palm 2010). As with many invasive species, non-native gobies also have the potential to disrupt natural systems, food web dynamics, and native species energetics. Competition between native and non-native species for food resources may be increasing energy expenditures of native fishes that could have detrimental effects to the long-term survival of native species. The reliance of harbor seals on invasive species may result in a decrease in nutritional health of harbor seals. Alternatively, harbor seals are serving a positive role by decreasing invasive species abundance. 
Gobies generally are nutritionally less rich than some native species in SFB. For instance, the caloric value of round goby (Neogobius melanos) from the Gulf of Gdańsk was approximately $1.5 \mathrm{kcal} / \mathrm{g}$ wet mass (Jakubas 2004) and considered of low energy density (Perez 1994). In contrast, many native species in SFB have a greater energy content, such as Pacific Herring (Clupea pallasi) (6.6kcal/g; Perez 1994), Northern Anchovies (4.8 kcal/g; Petza et al. 2006), and Starry Flounder (4.1 kcal/g; Ball et al. 2007).

Perhaps another indication of a decrease in prey species availability is the recent reliance of harbor seals on crangonid shrimp. Whereas shrimps and amphipods are found in the diet of some pinnipeds (Bluhm and Gradlinger 2008), crangonid shrimp do not provide the same nutritional content per mass for marine mammals as forage fish (Moore 1976, Percy and Fife 1980, Lawson et al. 1998, Bluhm and Gradlinger 2008). One species of crangonid shrimp, the Grass Shrimp Crangon franciscorum, had a caloric value of $3.4 \mathrm{kcal} / \mathrm{g}$ (Nelson et al. 1986). Although crangonid shrimp were not found in Torok's study (1994; Table 3), it is the seventh most important prey item in SFB (Table 4), and fifth greatest in prey importance for NSFB (Table 5).

The fish being taken by harbor seals are not large adult fish (Fig. 3); the average standard length for the top seven species of fish indicated that the average fish eaten was a juvenile. Additionally, other species that were in the diet in 1991/1992, such as Pile Perch (Rhacochilus vacca), have completely disappeared from the diet. A divergence in the diet from nutrient rich prey to nutrient poor abundant prey could be detrimental to the health and vitality of the predator. This phenomenon, often referred to as "the junk-food 
hypothesis" (Rosen and Trites 2000, Trites and Donnelly 2003), over time can result in a loss of protein content that causes muscle impairment and vital organ failure (Trites and Donnelly 2003, Jeanniard du Dot et al. 2008). There is no current evidence in the literature that suggests that average harbor seal weight or size has been decreasing in SFB. However, it would be a valuable metric to investigate further in the future.

In addition to energetic and nutritional compromises in adults due to low energy food and extended foraging trips, pups also may suffer as a result (Trillmich 1990, Trillmich and Dellinger 1991). Harbor seals in San Francisco Bay have experienced increased pup abandonment since 1975 (Lander et al. 2002). This could be attributed to reduction in local food resources for harbor seals, and may indicate increased nutritional stress for harbor seals with pups. Some female harbor seals off central California have not given birth following El Niño Years (when primary productivity is less), and numbers of pups produced in the overall population are less (Allen et al. 1989, Sydeman and Allen 1999).

Torok (1994) only investigated diet of harbor seals occupying SSFB, and although, the data were extremely useful, the results were not representative of harbor seals inhabiting the entire bay, as evidenced by this study. Because important prey items in this study differed between NSFB and SSFB, combining all locations represented the diet of seals in the entire bay but not specific locals. Combining locations provides an average representation of what is taken by harbor seals but does not highlight the distinct variability in diet between locations. Northern Anchovy was the most important species in the diet of harbor seals in NSFB, and Yellowfin Goby less important (Table 5, Figure 
9), whereas, Yellowfin Goby was most important in SSFB (Table 4, Figure 10) and Northern Anchovy were less important. Yellowfin Goby and Northern Anchovy were of greatest importance throughout the bay; however, they were important only in diets of some seals depending on location. It is, therefore, important to consider location when examining diet of harbor seals in the bay.

Harbor seals remain closer to haul-out sites during pupping season (Torok 1994, Nickel 2003) and eat what is readily available there. Prey species that were most important in the diet during the pupping season also were the species most available near haul-out sites based on a comparison with CDFG trawl data (Figure 11, 12).

Yellowfin Goby prefer the type of habitats found in SSFB (Workman and Merz 2007) and spawn from late February to early May (Pearson 1989, Baker 1979). The timing of the increase in Yellowfin Goby abundance directly correlates with pupping season in SSFB when females and weaners require prey of sufficient size and quantity. Shiner Surfperch was of importance during the pupping season in SSFB. This species spawns in spring coincident with the harbor seal pupping season, and the increase in abundance of this species also occurs at this time (Pearson 1989). In NSFB, Northern Anchovy was the most important prey species during the pupping season. Northern Anchovy spawn in open waters in the ocean and estuary and spawn year round with two major peaks in spawning and abundance in February-April and July-September (Wang 2010, Pearson 1989), the first peak of which coincides with the harbor seal pupping season for SFB. 
Harbor seals probably consume prey in proportion to that which is readily available in their environment, especially during the pupping season when seals are maintaining more fidelity to haul-out sites. This was evidenced by seasonal differences for NSFB. The diet became more varied during non-pupping season and the top four species had comparable importance in the diet (Table 5, Figure 9). During the pupping season the importance of Northern Anchovy in the diet increased and reliance on other species decreased. These increases in Northern Anchovy during pupping season (MarchJune) in the diet correlated to CDFG trawl data (Figure 13) where there was a large increase in the number of Northern Anchovy beginning in March. Although not anticipated, the diet became less varied during non-pupping season, however, these results also were consistent with trends between trawl data and diet data. During pupping season in SSFB there was an increase in importance on Shiner Surfperch. These increases directly correspond to increases in the CDFG trawls at the same time (Figs. 10, 13). The timing of the increase in both the diet and the trawls correlated with spawning behavior in the bay and habitat preference of Shiner Surfperch. This species enters the bay to spawn in spring and prefers shallow waters that can be found in SSFB (Love 1996).

Although diet and trawl data were statistically correlated, there were some noticeable differences. These differences were most pronounced between Plainfin Midshipman, Pacific Herring, Chameleon/Cheekspot Goby, and Yellowfin Goby. Plainfin Midshipman and Pacific Herring were better represented in the CDFG trawls than they were in the diet. The lack of Pacific herring in the diet may be due to spawning 
activity correlating to harbor seal pupping season. Pacific Herring come into SFB to spawn in late winter and early spring (Love 1996, Watters et al. 2004), which overlaps with the pupping season, when harbor seals exhibit restricted movements. Pacific Herring had large increases at this time (April through June; Fig. 13). Plainfin Midshipman use SFB for nesting in estuarine waters beginning in the summer months and leave the bay for deeper waters in the fall (Love 1996, Bland 2010), Plainfin Midshipman increased in the trawls in the summer and into the fall (Fig. 13), at a time when seals are more widely dispersed and may not be utilizing estuarine waters where the fish are nesting (Love 1996). Because they may not be using the areas where Plainfin Midshipman is nesting they may not be encountering them at a high rate. The fish then leave the bay in the fall and would only be encountered by harbor seals during long foraging trips.

Opposite of the trend for Plainfin Midshipman and Pacific Herring, harbor seal diet was more representative of some smaller species. Unfortunately, CDFG trawl data were biased for some species in SSFB (K. Hieb, personal communication, April 12, 2010). Smaller species like Yellowfin Goby, Chameleon/Cheekspot Goby, and Shiner Surfperch were not sampled effectively due to selectivity of trawl gear and the difficulty of sampling the shallow environment these species occupy (K. Hieb, personal communication, April 12, 2010). To detect pulses in these species, using seine nets in shallow waters would be a more effective sampling tool. These smaller species did not occur in great abundance during any time period in the CDFG trawl data, although they 
are more abundant during spawning (Pearson, 1989). For species that CDFG trawls did sample effectively, however, the data reflect what was found in the seal diet (Figure 7).

When comparing CDFG between decades, there were increases in non-native invasive species (Chameleon Goby, Yellowfin Goby), which is consistent with dietary findings. There also were decreases in native species (Northern Anchovy, White Croaker, Bay Goby). This may indicate a non-native species may be outcompeting native species.

The RBM tends to underestimate small prey that are consumed in medium quantities, and has a tendency to overestimate large prey items (Laake et al. 2002, Joy et al. 2006, Phillips and Harvey 2009). These biases are due to the fact that prey items are represented as a portion of biomass. Phillips and Harvey (2009) found that the RBM precisely estimated (within $3.4 \%$ of actual consumption) the amount of biomass consumed by harbor seals during captive trials. Using this model is appropriate if species-specific correction factors are attainable, and the all structures technique is applied (Phillips and Harvey 2009).

In this study, for many values of RBM and IRI for species were similar, however the RBM tended to overestimate Shiner Surfperch and underestimate Yellowfin Goby when compared with IRI estimates. Both of these prey items were relatively small in size. The discrepancy with the RBM may have occurred because this model tends to underestimate small prey. Starry flounder was considered a larger prey item, and were also overestimated by the RBM as compared with IRI values. This was expected due to the biases of the model. 
Knowledge of harbor seal diet provides a better understanding of prey species diversity and abundance in SFB. Because the diet is so distinctly different between north and south bay, future diet studies should concentrate on several high use haul-out areas, rather than localized sites in one area. There are many hypotheses as to why the population of harbor seals in the bay is not increasing compared with coastal colonies in California, depletion of local food sources being one. A combination of decreasing local prey availability, low food quality, elevated pollutant load, and lower immune system may compromise the health of individual seals, increase mortality, and decrease the population. Parental care and reproduction may also decline if adult harbor seals must spend more time and energy acquiring food resources for themselves and their young. As a result, the positive impacts of this apex predator may correspondingly decrease. 


\section{LITERATURE CITED}

Acũna HO, Francis JM. 1995. Spring and summer prey of the Juan Fernandez fur sea, Arctocephalus phillipii. Can. J. Zool. 73:1444-1452.

Alcorn D, Fancher L. 1980. Report on harbor seals of the San Francisco Bay National Wildlife Refuge, South San Francisco Bay, California. Final Report. Newark (CA): U.S. Department of Interior, Fish and Wildlife Service. Report No.: SFBNWR 80. Available from: USFWS, San Francisco, CA.

Allen SG. 1991. Harbor seal habitat restoration at Strawberry Split, San Francisco Bay. Report. Point Reyes (CA): Point Reyes Bird Observatory. Report No.: PB91212332/GAR. 47. Available from NPS, Point Reyes, CA.

Allen SG. 1993. Red-pelaged harbor seals of the San Francisco Bay Region. J. Mammal. 74(3):588-593.

Allen SG, Huber HR, Ribic CA, Ainley DG. 1989. Population dynamics of harbor seals in the Gulf of the Farallones, California. Calif. Fish Game. 75(4):224-232.

Arim M, DE Naya. 2003. Pinniped diets inferred from scats: analysis of biases in prey occurrence. Can. J. Zool. 81:67-73.

Baraff LS, Loughlin TR. 2000. Trends and potential interactions between pinnipeds and fisheries of New England and the U.S. West Coast. Mar. Fish. Rev. 62(4):1-39.

Baker JC. 1979. A contribution to the life history of the Yellowfin Goby (Acanthogobius flavimanus) in the San Francisco Bay-Delta Area [master's thesis]. [Sacramento (CA)]: California State University, Sacramento.

Ball JR, D Esler, JA Schmutz. 2007. Proximate composition, energetic value, and relative abundance of prey fish from the inshore eastern Bering Sea: implications for piscivorous predators. Polar Biol. 30:699-708.

Bland RW. 2010. Response of mating activity of the Plainfin Midshipman to inflow into San Francisco Bay from a summer storm [abstract]. American Geophysical Union, Fall Meeting; 2010 Dec 13-17; San Francisco (CA). Abstract: \#B31E0359. Available from: AGU, San Francisco, CA.

Bluhm BA, Gradinger R. 2008. Regional variability in food availability for arctic marine mammals. Ecol. Appl. 18(2):S77-S96.

Boness DJ, Bowen WD, Oftedal OT. 1994. Evidence of a maternal foraging cycle resembling that of otariid seals in a small phocid the harbour seal. Behav. Ecol. Sociobiol. 34:95-104. 
Boness DJ, Bowen WD, Buhleier BM, Marshall GJ. 2006. Mating tactics and mating system of an aquatic-mating pinniped: the harbor seal, Phoca vitulina. Behav. Ecol. Sociobiol. 61(1):119-130.

Bowen WD. 2000. Reconstruction of pinniped diets: accounting for complete digestion of otoliths and cephalopod beaks. Can. J. Fish. Aquat. Sci. 57:898-905.

Bowen WD, Boness DJ, Iverson SJ. 1999. Diving behaviour of lactating harbour seals and their pups during maternal foraging trips. Can. J. Zool. 77:978-988.

Bowen WD, Iverson SJ, Boness DJ, Oftedal, OT. 2001. Foraging effort, food intake and lactation performance depend on maternal mass in a small phocid seal. Funct. Ecol. 15(3):325-334.

Bowen WD, Tully D, Boness DJ, Bulheier BM, Marshall GJ. 2002. Prey-dependent foraging tactics and prey profitability in a marine mammal. Mar. Ecol. Prog. Ser. 244:235-245.

Boyle MD. 2010. Trophic relationships of Bathraja trachura and sympatric fishes [master's thesis]. [Monterey (CA)]: California State University, Monterey Bay.

Brittan MR, Albrecht AB, Hopkirk JD. 1963. An oriental goby collected in the San Joaquin River Delta near Stockton, California. Calif. Fish Game. 40(4):302-304.

Brown EG, Pierce GJ. 1998. Monthly variation in the diet of harbour seals in inshore waters along the southeast Shetland (UK) coastline. Mar. Ecol. Prog. Ser. 167:275-289.

Cailliet GM, Love M, Ebling A. 1986. Fishes: A Field and Laboratory Manual on their Structure, Identification and Natural History. $1^{\text {st }}$ ed. Long Grove (IL): Waveland Press Inc.

Carretta JV, Forney KA, Lowry MS, Barlow J, Baker J, Hanson B, Muto MM. 2007. US Pacific marine mammal stock assessments: 2007. Seattle (WA): National Oceanographic and Atmospheric Administration (US). Report No.: NOAA-TMNMFS-SWFSC-414. Available from: NMFS, Seattle, WA.

[CDFG] California Department of Fish and Game, cartographer. San Francisco Bay Study and the Interagency Ecological Program for the San Francisco Estuary, boat sampling stations [physical map]. San Francisco (CA): California Department of Fish and Game, San Francisco Bay Study and the Interagency Ecological Program for the San Francisco Estuary. 
Cortés E 1997. A critical review of methods of studying fish feeding based on analysis of stomach contents: application to elasmobranch fishes. Can. J. Fish. Aquat. Sci. $54: 726-738$.

Cottrell PE, Trites AW, Miller EH. 1996. Assessing the use of hard parts in faeces to identify harbor seal prey: Results of captive-feeding trials. Can. J. Zool. 74:875880 .

Cottrell PE, Trites AW. 2002. Classifying prey hard part structures recovered from fecal remains of captive stellar sea lions (Eumetopia jubatus). Mar. Mamm. Sci. 18(2):525-539.

Da Silva J, Neilson JD. 1985. Limitations of using otoliths recovered in scats to estimate prey consumption in seals. Can. J. Fish. Aquat. Sci. 42:1439-1442.

Feyrer F, Nobriga ML, Sommer TR. 2007. Multidecadal trends for three declining fish species: habitat patterns and mechanisms in the San Francisco Estuary, California, USA. Can. J. Fish. Aquat. Sci. 64:723-734.

Fretwell SD. 1977. The regulation of plant communities by the food chains exploiting them. Perspect. Biol. Med. 20:169-185.

Fretwell SD. 1987. Food Chain Dynamics: The Central Theory of Ecology? Oikos 50:291-301.

Friedlander AM, Parrish JD. 1998. Habitat characteristics affecting fish assemblages on a Hawaiian coral reef. J. Exp. Marine Biol. 224:1-30.

Grigg EK. 2003. Pacific harbor seals (Phoca vitulina richardii) in San Francisco Bay, California: a review of the literature. Oakland (CA): San Francisco Estuary Institute. Available from: San Francisco Estuary Institute, Oakland, CA.

Grigg EK, Allen SG, Green DE, Markowitz H. 2004. Harbor seals, Phoca vitulina richardii population trends in the San Francisco Bay Estuary, 1970-2002. Calif. Fish Game. 90(2):51-70.

Gotelli NJ, Ellison AM. 2004. A primer of ecological statistics. $1^{\text {st }}$ ed. Sunderland (MA): Sinauer Associates, Inc.

Hanan D 1996. Dynamics of abundance and distribution for Pacific harbor seal (Phoca vitulina richardii) on the coast of California [PhD Dissertation]. [Los Angles (CA)]: University of California, Los Angeles. 
Hammond PS, Rothery P. 1996. Application of computer sampling in the estimation of seal diet. J. Appl. Statist. 23:525-533.

Hariston NG, Smith FE, Slobodkin LB. 1960. Community structure, population control and competition. Amer. Nat. 94:421-425.

Harvey JT. 1987. Population dynamics, annual food consumption, movements and dive behaviors of harbor seals, Phoca vitulina richardii in Oregon [ $\mathrm{PhD}$ dissertation]. [Corvallis (OR)]: Oregon State University.

Harvey JT. 1989. Assessment of errors associated with harbor seal (Phoca vitulina) fecal sampling. J. Zool. 219:101-111.

Harvey JT, Loughlin TR, Perez MA, Oxman DS. 2000. Relationship between fish size and otolith length for 63 species of fishes from the Eastern North Pacific Ocean. Seattle (WA): National Oceanographic and Atmospheric Administration (US). Report No.: NMFS 150. Available from: NMFS, Seattle, WA.

Herald ES, Eschmeyer WN. 1983. Pacific coast fishes guide. $1^{\text {st }}$ ed. New York (NY): Houghton Mifflin Co.

Hume F, Hindell MA, Pemmberton D, Gales R. 2004. Spatial and temporal variation in the diet of a high trophic level predator, the Australian fur seal (Arctocephalus pusillus doriferus). Mar. Biol. 144:407-415.

Hyslop EG. 1980. Stomach content analysis - a review of methods and their applications. J. Fish. Biol. 17:411-429.

Jakubas D. 2004. The response of the grey heron to a rapid increase of the Round Goby. Waterbirds. 27(3):304-307.

Jeanniard du Dot T, Rosen AS, Trites AW. 2008. Stellar sea lions show diet-dependent changes in body composition during nutritional stress and recover more easily from mass lost in winter than in summer. J. Exp. Marine Biol. 367:1-10.

Jobling M, Breiby A. 1986. The use and abuse of fish otoliths in studies of feeding habits of marine piscivores. Sarsia. 72(3-4):255-260.

Joy R, Tollit DJ, Laake L, Trites AW. 2006. Using feeding trials and computer simulations to reconstruct pinniped diet from scat. In: Trites AW, Atkinson S, DeMaster DP, Fritz LW, Gelatt TS, Rea LD, Wynne K, editors. Sea lions of the world. $1^{\text {st }}$ ed. Fairbanks (AK): Alaska Sea Grant College Program, University of Alaska. p. 205-222. 
Kopec D, Harvey JT. 1995. Toxic pollutants, health indices, and population dynamics of harbor seals in San Francisco Bay, 1989-91: a final report. Moss Landing (CA): Moss Landing Marine Laboratories (US). Report No.: 96-4. Available from: MLML, Moss Landing, CA.

Krebs CJ. 1999. Ecological methodology. $2^{\text {nd }}$ ed. Menlo Park (CA): Addison-Welsey Educational Publishers.

Krone RB. 1996. Recent sedimentation in the San Francisco Bay system. In: Hollibaugh JT, editor. San Francisco Bay: the ecosystem: further investigations into the natural history. $1^{\text {st }}$ ed. Altona (MB): Friesen Printers. p. 85-96.

Laake JL, Browne P, DeLong RL, Huber HR. 2002. Pinniped diet composition: a comparison of estimation models. Fish. Bull. 100(3):434-447.

Lance MM, Orr AJ, Riemer SD, Weise MJ, Laake JL. 2001. AFSC Processed Report 2001-2004: pinniped food habits and prey identification protocol. Seattle (WA): National Oceanographic and Atmospheric Administration (US). Available from: NMFS, Seattle, WA.

Lander ME, Harvey JT, Hanni KD, Morgan LE. 2002. Behavior, movement and apparent survival of rehabilitated and free ranging harbor seal pups. J. Wildl. Manage. 66(1):19-28.

Lawson JW, Magalhaes AM, Miller EH. 1998. Important prey species of marine vertebrate predators in the northwest Atlantic: proximate composition and energy density. Mar. Ecol. Prog. Ser. 164:13-20.

Love RM. 1996. Probably more than you want to know about the fishes of the pacific coast. $1^{\text {st }}$ ed. Santa Barbara (CA): Really Big Press.

Marcus JD, Bowen W, Eddington JD. 1998. Effects of meal size on otolith recovery from fecal samples of grey and harbor seal pups. Mar. Mamm. Sci. 14(4):789802 .

McCoy ED, Bell SS. 1991. Habitat structure: the evolution and diversification of a complex topic. In: Bell SS, McCoy ED, Mushinsky HR, editors. Habitat Structure: the Physical Arrangement of Objects in Space. $1^{\text {st }}$ ed. New York (NY): Chapman and Hall. p. 3-27.

Moore JW. 1976. The proximate and fatty acid composition of some estuarine crustaceans. Estuar. Coast. Mar. Sci. 4(2):215-224. 
Murie DJ, Lavigne DM. 1985. A technique for the recovery of otoliths from stomach contents of piscivorous pinnipeds. J. Wildl. Manage. 49:910-912.

Nelson NC, Simmons MA, Knight AW. 1986. The energy burden of the bopyrid parasite Argeia pauperata on the grass shrimp Crangon franciscorum. Comp. Biochem. Physiol. A. 83(1):121-124.

Nickel BA. 2003. Movement and habitat use patterns of harbor seals in the San Francisco Estuary, CA [master's thesis]. [San Francisco (CA)]: San Francisco State University.

Olesiuk PF. 1993. Annual prey consumption by harbor seals (Phoca vitulina) in the Strait of Georgia, British Columbia. Fish. Bull. 91:491-515.

Olesiuk PF, Bigg MA, Ellis GM, Crockford SJ, Wigen RJ. 1990. An assessment of the feeding habits of harbour seals (Phoca vitulina) in the Strait of Georgia, British Columbia, based on scat analysis. Vancouver (BC): Fisheries and Oceans Canada (Canada). Report No.: 99/33. Available from: Fisheries and Oceans Canada, Vancouver, BC, Canada.

Orr AJ, Laake JL, Dhruv MI, Banks AS, Delong RI, Huber HR. 2003. Comparison of processing pinniped scat samples using a washing machine and nested sieves. Wildl. Soc. Bull. 31(1):253-257.

Orr AJ, Harvey JT. 2001. Quantifying errors associated with using fecal samples to determine the diet of the California sea lion (Zalophus californianus). Can. J. Zool. 79:1080-1087.

Oxman DS. 1995. Seasonal abundance, movements, and food habits of harbor seals (Phoca vitulina richardii) [master's thesis]. [Stanislaus (CA)]: California State University, Stanislaus.

Paine RT. 1966. Food web complexity and species diversity. Amer. Nat. 100(910):65-75.

Pearson DE. 1989. Survey of fishes and water properties of south San Francisco Bay, California, 1973-82. Seattle (WA): National Oceanographic and Atmospheric Administration (US). Report No.: NMFS 78. Available from: NMFS, Seattle, WA.

Percy JA, Fife FJ. 1980. The proximate composition and caloric content of arctic marine invertebrates from Frobisher Bay. Vancouver (BC): Fisheries and Oceans Canada (Canada). Report No.: 214. Available from: Fisheries and Oceans Canada, Vancouver, BC, Canada. 
Perez MA. 1994. Calorimetry measurements of energy value of some Alaskan fishes and squids. Seattle (WA): National Oceanographic and Atmospheric Administration (US). Report No.: NMFS_AFSC-32. Available from: NMFS, Seattle, WA.

Petza DS, Katsanevakis S, Verriopoulos G. 2006. Experimental evaluation of the energy balance in Octopus vulgaris, fed ad libitum on a high-lipid diet. Mar. Biol. 148:827-832.

Phillips E. 2005. Results of a captive feeding study with the Pacific harbor seal (Phoca vitulina richardii): Implications for scat analysis [master's thesis]. [San Francisco (CA)]: San Francisco State University.

Phillips E, Harvey JT. 2009. A captive feeding study with the Pacific harbor seal (Phoca vitulina richardii): Implications for scat analysis. Mar. Mamm. Sci. 25(2):373391.

Pinkas L, Oliphant MS, Iverson ILK. 1971. Food habits of albacore, Bluefin Tuna, and Bonito in California waters. Fish. Bull. 152:1-33.

Pitcher TJ. 1980. Some ecological consequences of fish school volumes. Freshwat. Biol. 10:539-544.

Petzrick EP, Collins CA, Boicourt WC. 1996. Currents through the golden gate. In: Hollibaugh JT, editor. San Francisco Bay: the ecosystem: further investigations into the natural history. $1^{\text {st }}$ ed. Altona (MB): Friesen Printers. p. 105-122.

Read AJ, Drinker P, Northridge S. 2006. Bycatch of marine mammals in U.S. and global fisheries. Conserv. Biol. 20(1):163-169.

Reeves RR, Stewart BS, Clapham PJ, Powell JA. 2002. National Audubon Society guide to marine mammals of the world. $1^{\text {st }}$ ed. New York (NY): Alfred A. Knopf.

Risebrough RW, Alcorn D, Allen SG, Anderlini VC, Booren L, Delong RL, Fancher LE, Jones RE, McGinnis SM, Schmidt TT. 1979. Population biology of harbor seals in San Francisco Bay, California. Washington DC (federal district): The Marine Mammal Commission (US). Contract No.: MM64C006. Available from: The Marine Mammal Commission, Washington, DC.

Roffe TJ, Mate BR. 1984. Abundances and feeding habits of pinnipeds in the Rogue River, Oregon. J. Wildl. Manag. 48(4):1262-1274.

Rosen DAS, Trites AW. 2000. Pollock and the decline of Steller sea lions: testing the junk-food hypothesis. Can. J. Zool. 78:1243-1250. 
Smith SE, Kato S. 1979. The fisheries of San Francisco Bay: past, present, and future. In: Conomos TJ, Levitan AE, Berson M, editors. San Francisco Bay: the urbanized estuary. $1^{\text {st }}$ ed. San Francisco (CA): California Academy of Sciences. p. 445-468.

Sokal RR, Rohlf FJ. 1995. Biometry: the principles and practice of statistics in biological research. 3rd ed. New York (NY): W.H. Freeman.

Sydeman WJ, Allen SG. 1999. Pinniped population dynamics in Central California: correlations with sea surface temperature and upwelling indices. Mar. Mamm. Sci. 15(2):446-461.

[TBIES] The Bay Institute Ecological Scorecard. 2003. San Francisco Bay fish index, indicator analysis and evaluation [Internet]. San Francisco (CA): The Bay Institute (US). [cited 2006 August 18]. Available from: http://www.bay.org/assets/2003.Bay.Index.Report.pdf

[TBIES] The Bay Institute Ecological Scorecard. 2005. San Francisco Bay Fish Index, Indicator analysis and evaluation [Internet]. San Francisco (CA): The Bay Institute (US). [cited 2007 Mar 4]. Available from: http://www.bay.org/assets/2005.Bay.Index.Report.pdf

Tollit DJ, Steward MJ, Thompson PM, Pierce GJ, Santos MB, Hughes S. 1997. Species and size differences in the digestion of otoliths and beaks: implications for estimates of pinniped diet composition. Can. J. Fish. Aquat. Sci. 54:105-119.

Torok ML. 1994. Movements, daily activity patterns, dive behavior, and food habits of harbor seals (Phoca vitulina richardii) [master's thesis]. [Stanislaus (CA)]: California State University, Stanislaus.

Trillmich F. 1990. The behavioral ecology of maternal effort in fur seals and sea lions. Behaviour. 114:3-20.

Trillmich F, Dellinger T. 1991. The effects of el niño on Galapagos pinnipeds. In: Trillmich F, Ono AK, editors. Pinnipeds and el niño: responses to environmental stress. $1^{\text {st }}$ ed. Berlin (Germany): Springer-Verlag. p. 66-74.

Trites AW. 2003. Food webs in the ocean: who eats whom and how much? In: Sinclair M, Valdimarsson G, editors. Responsible fisheries in the marine ecosystem. $1^{\text {st }}$ ed. Wallingford (UK): FAO Rome and CABI Publishing. p. 1-16.

Trites AW, Donnelly CP. 2003. The decline of Steller sea lions Eumetopias jubatus in Alaska: a review of the nutritional stress hypothesis. Mammal Rev. 33:3-28. 
Utne-Palm AC, Salvanes AGV, Currie B, Kaartvedt S, Nilsson GE, Braithwaite VA, Stecyk JAW, Hundt M, van der Bank M, Flynn B, Sandvik GK, Klevjer TA, Sweetman AK, Brüchert V, Pittman K, Peard KR, Lunde IG, Strandabǿ RAU, Gibbons MJ. 2010. Trophic structure and community stability in an overfished ecosystem. Science. 329:333-336.

Van Parijs SM, Thompson PM, Tollit DJ, Mackay A. 1997. Distribution and activity of male harbour seals during the mating season. Anim. Behav. 54:35-43.

Wang JCS. 2010. Fishes of the Sacramento-San Joaquin Estuary and adjacent waters, California: A guide to the early life histories. Byron (CA): US Department of the Interior, Mid-Pacific Region (US). Report No.: 9. Available from: Interagency ecological study program for the Sacramento-San Joaquin Estuary, Byron, CA.

Watters DL, Brown HM, Griffin FJ, Cherr GN. 2004. Pacific Herring Spawning Grounds in San Francisco Bay: 1973-2000. In: Feyrer F, Brown LR, Brown RL, Orsi JJ, editors. Early life history of fishes in the San Francisco estuary and watershed. $1^{\text {st }}$ ed. Bethesda (MD): American Fisheries Society. p. 3-14.

Wootton JT, Power ME, Parker MS. 1996. Effects of disturbance on river food webs. Science. 273:1558-1561.

Workman ML, Merz JE. 2007. Introduced Yellowfin Goby, Acanthogobius flavimanus: diet and habitat use in the Lower Mokelumne River, California. San Fran. Estuar. Water Sci. 5(1):1-13.

Zar JH. 1999. Biostatistical Analysis. $4^{\text {th }}$ ed. Upper Saddle River (NJ): Prentice-Hall, Inc. 